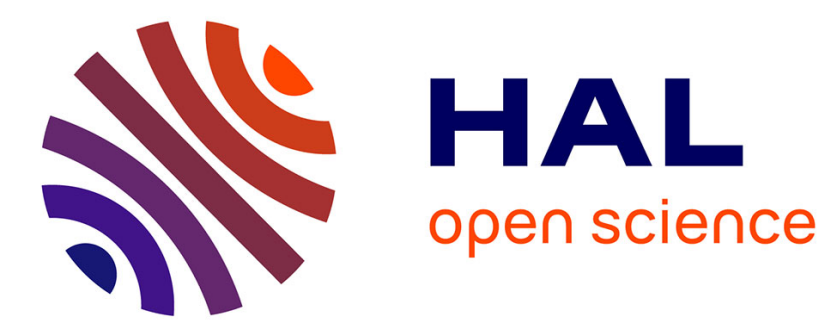

\title{
Component-Based Model Versus Stress-Resultant Plasticity Modelling of Bolted End-Plate Connection: Numerical Implementation
}

\author{
Anas Alhasawi, Samy Guezouli, Maël Couchaux
}

\section{- To cite this version:}

Anas Alhasawi, Samy Guezouli, Maël Couchaux. Component-Based Model Versus Stress-Resultant Plasticity Modelling of Bolted End-Plate Connection: Numerical Implementation. Structures, 2017, 11, pp.164-177. 10.1016/j.istruc.2017.05.004 . hal-01617152

HAL Id: hal-01617152

https://hal-univ-rennes1.archives-ouvertes.fr/hal-01617152

Submitted on 16 Oct 2017

HAL is a multi-disciplinary open access archive for the deposit and dissemination of scientific research documents, whether they are published or not. The documents may come from teaching and research institutions in France or abroad, or from public or private research centers.
L'archive ouverte pluridisciplinaire HAL, est destinée au dépôt et à la diffusion de documents scientifiques de niveau recherche, publiés ou non, émanant des établissements d'enseignement et de recherche français ou étrangers, des laboratoires publics ou privés. 


\title{
Accepted Manuscript
}

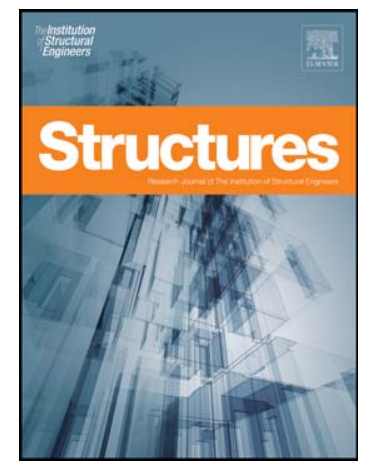

Component-based model versus stress-resultant plasticity modelling of bolted end-plate connection: Numerical implementation

\author{
Anas Alhasawi, Samy Guezouli, Maël Couchaux \\ PII: \\ DOI: \\ S2352-0124(17)30031-0 \\ Reference: \\ doi: 10.1016/j.istruc.2017.05.004 \\ ISTRUC 195
}

To appear in:

Received date: 6 January 2017

Revised date: $\quad 18$ May 2017

Accepted date: $\quad 22$ May 2017

Please cite this article as: Alhasawi Anas, Guezouli Samy, Couchaux Maël, Componentbased model versus stress-resultant plasticity modelling of bolted end-plate connection: Numerical implementation, (2017), doi:10.1016/j.istruc.2017.05.004

This is a PDF file of an unedited manuscript that has been accepted for publication. As a service to our customers we are providing this early version of the manuscript. The manuscript will undergo copyediting, typesetting, and review of the resulting proof before it is published in its final form. Please note that during the production process errors may be discovered which could affect the content, and all legal disclaimers that apply to the journal pertain. 


\title{
Component-based model versus stress-resultant plasticity modelling of bolted end-plate connection: Numerical implementation
}

\author{
Anas Alhasawi ${ }^{1}$, Samy Guezouli ${ }^{1}$ and Maël Couchaux ${ }^{1}$ \\ ${ }^{1}$ INSA de Rennes, LGCGM/Structural Engineering Research Group, 20 avenue des Buttes de Coësmes, \\ CS 70839, 35708 Rennes Cedex 7, France
}

\begin{abstract}
This paper deals with the analysis of a steel beam-to-column bolted end-plate connection subjected to cyclic loading. The proposed model consists of an improved component-based approach that closely follows the joint behavior. The study reminds the component-based analysis and shows how to implement two proposed improvements by the use of an elastoplastic formulation and discuss their influences on the joint behavior. The first modification concerns possible separation between the end-plate and the column flange on which it is bolted (gap effect) and the second one concerns the group of two or more than two boltrows (group effect). Examples are subsequently detailed for validation and highlight the robustness of the proposed model. These modifications allows to the well-known component based model a new variant that gives more accurate results and remains easy-to-implement in structural analysis programs.
\end{abstract}

Keywords : Steel joint connection, cyclic load, component-based model, gap problem, group effect, Finite Element Method

\section{Introduction}

Safe and economic design of steel and composite structures requires a deep understanding of the joint response. Semi-rigid connections can provide several advantages including : economy and fabrication costs, robustness of the frames, ... Two different approaches have been adopted to model the behavior of semi-rigid connections, one can distinguish between:

- Theoretical models: these models propose empirical or semi-empirical Moment-Rotation curves generally fitted of experimental test data. Parameters of these models are often related to material/geometrical characteristics of the joint. They are formulated in a way to ease their implementation in a standard displacement-based analysis of frame. A nonlinear finite element analysis of frames considering the actual joint behavior provides a more accurate representation of the structure deformation and the corresponding internal forces. Significant improvements have been made to this approach since the 1980s with: Richard et al. [1] proposed to include experimental curves directly in a finite element procedure; several authors proposed multi-linear curves still dependent on a mathematical curve fitting such as: Moncarz and Gerstle [2] in 1981, 
Poggi and Zandonini [3] in 1985, Nethercot [4] in 1989, ... . The FEM has been used to investigate the joint behavior; $2 \mathrm{D}$ and $3 \mathrm{D}$ models have been developed by different authors such as: Patel and Chen [5] in 1985 for bolted connections, Bursi and Jaspart [6] in 1997, Yang et al. [7] in 2000, Maggi et al. [8] in 2002 and more recently, Concepcion Diaz et al. [9] in 2011, Bo Yang and Kang Hai Tan [10] in 2012. All these results were used to obtain mathematical equations for the moment-rotation curves.

- Mechanical models: These models well-known as the component-based models appear as a viable alternative between semi-empirical models and complicated 3D ones. The basic idea is to distinguish within a joint a set of individual components. Each component is characterized by its own mechanical behavior (stiffness, strength, deformability, ...). Main developments have been proposed by Jaspart [11] in 1996, Jaspart et al. [12] in 1999, Cerfontaine [13] in 2004, Del Savio et al. [14] in 2009, Bayo et al. [15] in 2006, Minas et al. [16] in 2009 and Chang et al. [17] in 2015. Component-based mechanical models use tension/compression springs connected to rigid links. Each spring reproduces the behavior of a component inside the joint resisting either in tension or in compression. The models proposed by different authors concern various types of connections (welded, double seats, bolted, ...).

Most of the above described models have been developed to describe the joint behavior under monotonic loading. Generally, these studies focused mainly on the evaluation of the resisting bending moment, the rotational stiffness and the rotational capacity (ductility) of the joint. However, some of these theoretical models were adapted to reproduce the mechanical response of connection under cyclic loading: Moncarz and Gerstle [2] in 1981 and Mazzolani [18] in 1988. In this paper, The mechanical response of joints under cyclic loading has been investigated using a component-based model. Gang Shi et al. [19] undertook several experimental tests on different typologies of bolted end-plate connection. This investigation has been focused on the comparison between flush and extended end-plate configurations: considering different end-plate thicknesses, bolt diameters, number of bolts and including or not stiffeners. Some specimens have been tested under monotonic and cyclic loading. Under cyclic loading, one can observe that in case of a flush end-plate joint, the gap between the column flange and the end-plate is more significant than in case of an extended end-plate connection (specimen JD1). Pu Yang et al. [20] proposed a model for bolted extended en-plate connection to describe the joint behavior under cyclic loadings. The model includes linear springs connected to a rotational spring for beam plastic hinge on one side and a rotational spring for the column panel in shear on the other side. The simulations were compared to six full-scale experiments. One can observe that the experimental results (specimen ES-1-1/2-24a) show evidence of an end-plate separation at the bottom of the beam flange. It appears that this separation (gap) has a significant influence on the bending moment. More recently, Da Silva et al. [21] in 2016 proposed a cyclic component-based model. The proposed model concerns steel joints subjected to a bending moment. Under cyclic loading, the proposed model included the possibility of load reversal for any rotation magnitude. The objective is to reproduce the hysteretic behavior with degradation of performance. Possible separation (gap) is not discussed. To conclude for the bolted end-plate 
connection, it appears that the literature does not give efficient mechanical models able to accurately reproduce the joint behavior under cyclic loading. The newly proposed model concerning this paper includes two aspects that significantly influence the joint behavior:

- The separation (gap) between the column flange and the end-plate and its effect on the global behavior of the joint. This phenomenon should take into account the collapse models of the T-stub as defined in Eurocode 3 [23].

- The group effect of some bolt-rows and how to include it within the plasticity algorithm. We remind that Eurocode 3 [23] takes into account the group effect through the limit resistance of the bolt-rows only.

From a computational view point, the constitutive equations for each component are discretized using an implicit scheme and the consistent stiffness matrix for the joint is derived using a standard assemblage procedure.

\section{Component-based analysis}

The main idea of this approach is to reflect each source of deformation within the joint by a nonlinear spring and combine them within an arrangement to best reproduce the mechanical response of the connection. This method requires the following steps:

- Identification of active component,

- Evaluation of the force deformation response of each component,

- Assembly of the active components for the evaluation of the whole joint response.

Fig. 1 shows the connection and its corresponding mechanical model. The components which contribute to the deformation of the bolted beam-to-column connection are defined in Table 1.

Notice: The component BWT does not appear in the Fig. (1) because this component is considered only for the bolt-rows located between the beam flanges. Indeed, in Fig. (1),

Table 1: List and effect of different components

\begin{tabular}{|c|l|}
\hline Symbols & Components \\
\hline CWT & Column Web in Tension \\
\hline CFB & Column Flange in Bending \\
\hline EPB & End-Plate in Bending \\
\hline BWT & Beam Web in Tension \\
\hline BT & Bolt in Tension \\
\hline CWC & Column Web in transverse Compression \\
\hline BFWC & Beam Flange and Web in Compression \\
\hline
\end{tabular}




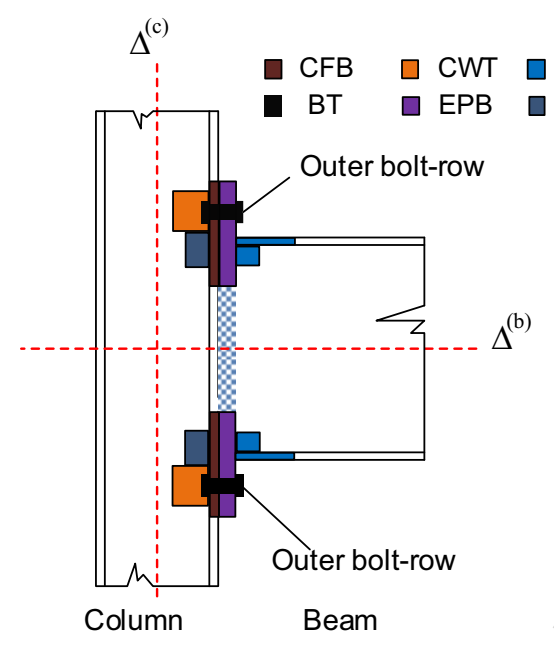

a) End-plate connection

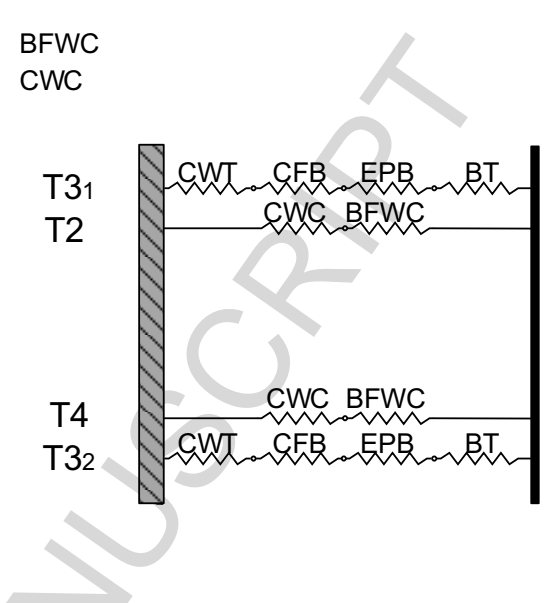

b) Mechanical Model

Figure 1: Components effects and corresponding springs - equivalent springs "Types, $r$ "

the joint configuration is double extended end-plate without bolt-rows between the beam flanges, so no component "BWT" in this configuration.

\subsection{Joint Type characterisation}

Each set of individual springs in series is replaced by an equivalent spring denoted "Type", in order to distinguish with individual components denoted "component" (see Fig. 1). Each equivalent spring is identified with a label depending on its location. The corresponding activation mode (tension or compression) is highlighted. Each Type can be defined as follows:

- T2 and T4 are the compression equivalent springs located at the beam flanges. They both contain the same components. $T 2$ is located at the top beam flange level and $T 4$ at the bottom one.

- $T 3_{i}$ concerns bolt-rows $i=1, \ldots, m$ that work only in tension. During the cyclic loading only the bolt-rows being in tension are activated, the others are temporarily disabled.

The force-displacement relationship of each Type within the joint may be characterized by a bi-linear, tri-linear or non-linear curve. In this study, we consider a bi-linear elastic perfectly plastic model obtained by assembling all relevant components. Each component (individual spring) behave elastically except the end-plate and the column flange in bending which have an elastic-perfectly plastic behaviour. For each component " $\alpha$ " the initial stiffness $k^{\alpha}$ and the plastic resistance $F_{R d}^{\alpha}$ are calculated according to Eurocode 3 [23]. Considering the index " $T$ " related to "Type" and " $r$ " to its number, the plastic strength for each Type $F_{T r, R d}$ is the minimum between individual plastic resistances of the concerned components: 
$F_{T r, R d}=\underset{\alpha=1, \ldots, n_{c}}{\operatorname{Min}}\left(F_{R d}^{\alpha}\right)$, where $n_{c}$ is the number of components in the corresponding Type. The stiffness of the Type $k_{T r}$ can be calculated as follows:

- The stiffness of $T 2$ (or T4) is obtained by condensing out the internal degree of freedom (Fig. 2).

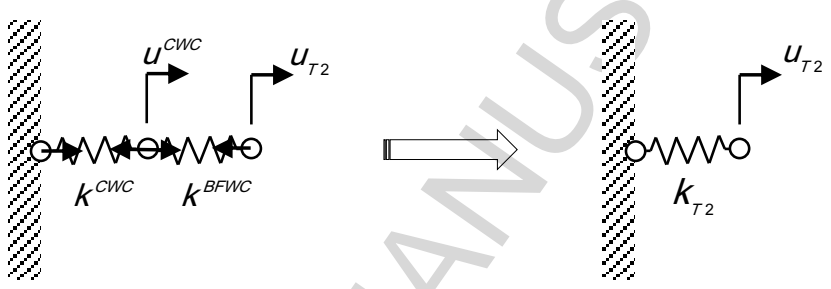

Figure 2: Equivalent component - T2 (or T4)

$$
k_{T 2 / T 4}=\frac{1}{\sum_{\alpha}^{n_{c}} \frac{1}{k^{\alpha}}}=\frac{1}{\frac{1}{k^{C W C}}+\frac{1}{k^{B F W C}}}=\frac{k^{B F W C} k^{C W C}}{k^{B F W C}+k^{C W C}}
$$

- The stiffness of $T 3_{i}$ is obtained by condensing out internal degrees of freedom (Fig. 3). The index " $i$ " is added for each Type 3 including bolt-rows and corresponding number in the joint ( $i=1$ for the top bolt-row, $i=m$ for the last bottom bolt-row).

$$
k_{T 3_{i}}=\frac{1}{\sum_{\alpha}^{n_{c}} \frac{1}{k^{\alpha}}}=\frac{1}{\frac{1}{k^{C W T}}+\frac{1}{k^{C F B}}+\frac{1}{k^{E P B}}+\frac{1}{k^{B T}}}
$$

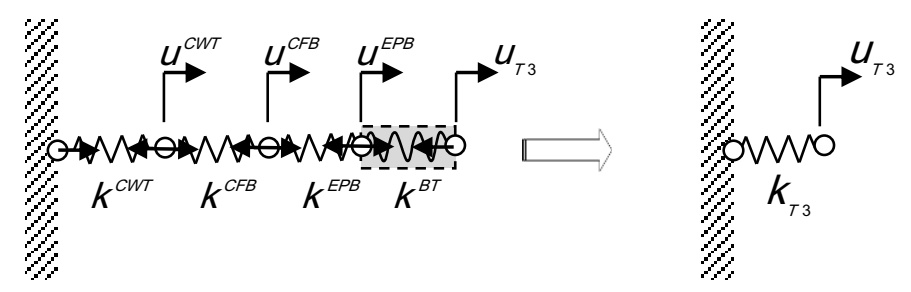

Figure 3: Equivalent component $-T 3_{i}$

\section{Mechanical model formulation}

The proposed mechanical model consists of two rigid links, the left one represents the column web centerline and the right one represents the end-beam line. These lines are 


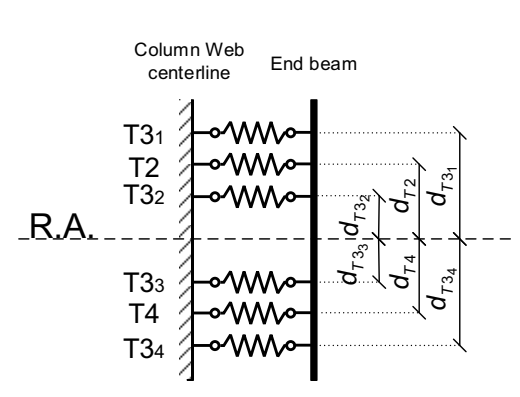

a - Initial configuration
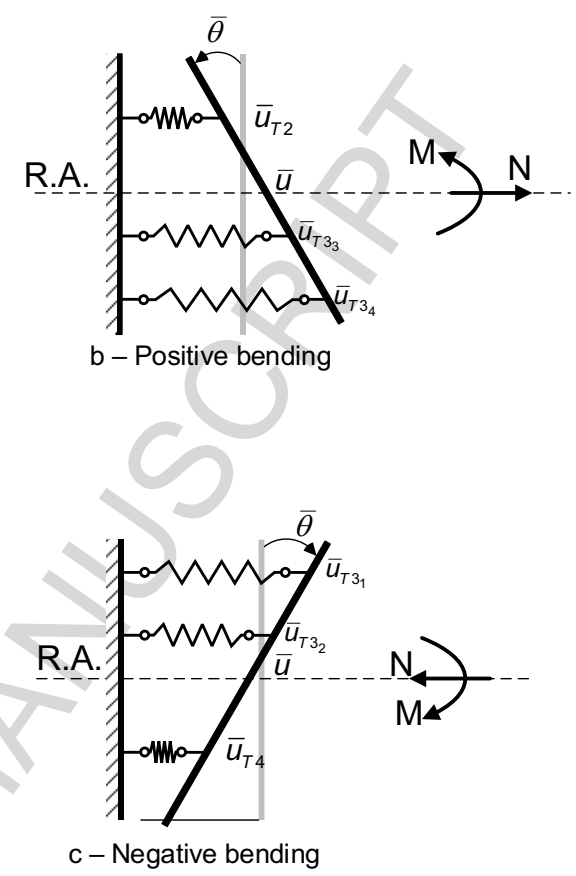

Figure 4: Proposed mechanical model

connected by series of springs that are replaced by spring Types: $T_{r}$. The details of the proposed mechanical model are given in Fig. 4 and an example of a deformed state in both cases negative and positive bending (Fig. 4b and Fig. 4c). The index $i$ of the bolt-row begins from the top. In case of negative bending, only $T 3_{1}, T 3_{2}$ and $T 4$ are activated and the others are temporarily disabled. At each " $r$ " level, the lengthening (shortening) $\bar{u}_{T r}$ are highlighted and at the reference axis (R.A.) the global variables of the joint are represented by the couple $(\bar{u}, \theta)$ : axial displacement and relative rotation. These variables are related to the applied loads $(N, M)$ : axial force and bending moment, respectively. In the case of positive bending, Fig. (4b), $T 3_{3}, T 3_{4}$ and $T 2$ will be activated and the others will be disabled. The global force vector is defined as follows:

$$
\mathbf{F}=\left\{\begin{array}{ll}
N & M
\end{array}\right\}^{T}
$$

and corresponding global displacement vector is:

$$
\boldsymbol{U}=\left\{\begin{array}{ll}
\bar{u} & \bar{\theta}
\end{array}\right\}^{T}
$$

The displacement of each $\operatorname{Tr}$ can be geometrically calculated assuming small local rotations, as follows:

$$
\begin{aligned}
& \bar{u}_{T 3_{i}}=\bar{u}-d_{T 3_{i}} \bar{\theta} \quad \Leftrightarrow \quad \bar{u}_{T 3_{i}}=\left\{\begin{array}{ll}
1 & -d_{T 3_{i}}
\end{array}\right\} \boldsymbol{U} \\
& \bar{u}_{T 2}=\bar{u}-d_{T 2} \bar{\theta} \quad \Leftrightarrow \quad \bar{u}_{T 2}=\left\{\begin{array}{ll}
1 & -d_{T 2}
\end{array}\right\} \boldsymbol{U}
\end{aligned}
$$


In the above equations, $d_{T r}$ are the vertical coordinates of the corresponding Type $r$, positive value for the Type above the reference axis and negative value for those under the reference axis.

The stiffness matrix of the mechanical model is obtained by the use of the principle of virtual work. The equilibrium equation between the variation of the internal virtual work, $\delta W^{\text {int }}$, and external one, $\delta W^{e x t}$ is defined by:

$$
\delta W^{\text {int }}=\delta W^{e x t}
$$

where:

$$
\delta W^{\mathrm{int}}=\sum_{r} \delta \overline{\boldsymbol{u}}_{T r}^{T} \boldsymbol{k}_{T r} \overline{\boldsymbol{u}}_{T r}+\sum_{i}^{n} \delta \overline{\boldsymbol{u}}_{T 3_{i}}^{T} \boldsymbol{k}_{T 3_{i}} \overline{\boldsymbol{u}}_{T 3_{i}}
$$

The first term of Eq (8) corresponds to the virtual work of activated top or bottom beam flange rows ( $r=2$ or 4 ), whilst the second term represents the virtual work of all activated bolt-rows.

External virtual work is given by:

$$
\delta W^{e x t}=\delta \mathbf{U}^{T} \mathbf{F}
$$

replacing (5) into (8) and substituting it with (9) into (7), it leads to:

$$
\left[\begin{array}{ll}
C_{11} & C_{12} \\
C_{12} & C_{22}
\end{array}\right]\left\{\begin{array}{l}
\bar{u} \\
\bar{\theta}
\end{array}\right\}=\left\{\begin{array}{l}
N \\
M
\end{array}\right\}
$$

where:

$$
\begin{aligned}
& C_{11}=\sum_{r} k_{T r}+\sum_{i}^{m} k_{T 3_{i}} \\
& C_{12}=-\sum_{r} k_{T r} d_{T r}-\sum_{i}^{m} k_{T 3_{i}} d_{T 3_{i}} \\
& C_{22}=\sum_{r} k_{T r} d_{T r}^{2}+\sum_{i}^{m} k_{T 3_{i}} d_{T 3_{i}}^{2}
\end{aligned}
$$

The model uses a displacement control procedure to solve the non-linear system of equations, Eqs. (10), (mechanical non-linearity).

\section{Cyclic behaviour of bolted end-plate connection}

A general model of a beam-to-column joint should include a component related to the column shear deformation, Fig. 5. The total rotation of the end-beam cross-section is therefore the sum of the column centerline rotation $\gamma$ and the end-beam cross-section rotation relatively to column centerline $\theta$. During cycling loading, each activated bolt-row is loaded in 
tension and it elongates according to its own stiffness. In the elastic domain, the gap vanishes once the equivalent spring is unloaded. By increasing the load, if the end-plate or the column flange component is in plastic range, a permanent gap appears. An accurate componentbased model should be able to follow the evolution of this gap and the deformation during the loading history.

The gap rotation is provided by relative deformation of the end-pate in bending, the column

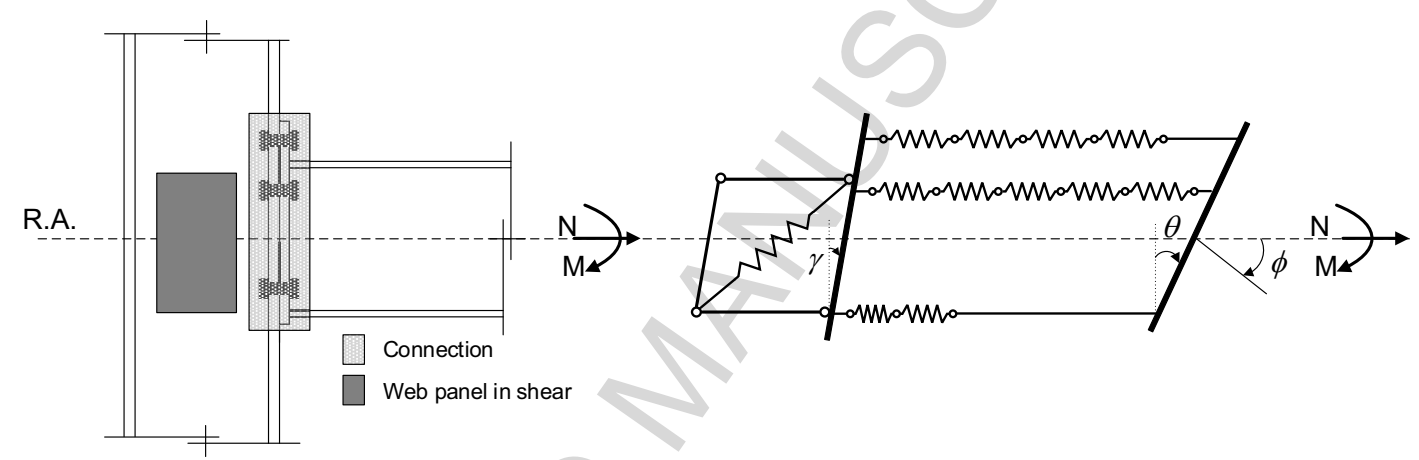

Figure 5: General mechanical model for the joint

flange in bending and the bolt in tension. This individual components that related to the gap rotation are characterized in the component method based on the T-stub model. An example of 3D finite element simulation show clearly that a gap might occur between the column flange and the end-plate due to plastic deformations (Fig. 6).

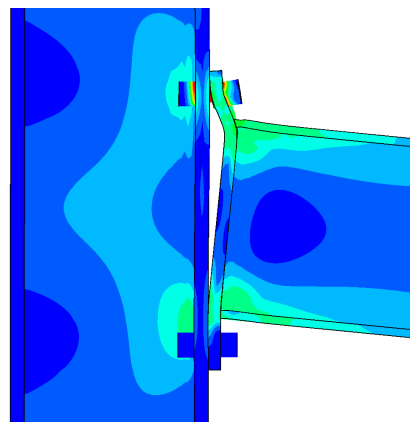

Figure 6: The gap - 3D finite element model

\subsection{Joint mechanical response during cyclic loading}

In the aim to simplify the analysis of the joint behaviour under cyclic loading, the case of two bolt-rows is considered. This analysis could be easily extended to the case of more then two bolt-rows.

It is worth to mention that the specimen is loaded firstly by a negative rotation Fig. 7 followed by a positive rotation Fig. 8. The following stages can be distinguish: 
- Stage 1 - loading in negative bending: Top bolt-row $T 3_{1}$ is in tension. Assuming that the gap at this top level $g_{t}$ occurs due to plastic deformations of one or both components (EPB and/or CFB see Table 1) of $T 3_{1}$.

- Stage 2 - Unloading from negative bending: Previous plastic deformation remain permanent in corresponding component(s). In order to close the gap $g_{t}$, a slip must occur in the behaviour curve $\left(F_{T 3_{1}}-\bar{u}_{T 3_{1}}\right)$, Fig. $7(\mathrm{c})$. This slip allows the bottom bolt-row $T 3_{2}$ to be activated.

- Stage 3 - Loading in positive bending: Bottom bolt-row $T 3_{2}$ is in tension and the top one $T 3_{1}$ is disabled. Assuming that the gap at this bottom level $g_{b}$ occurs due to plastic deformations of one or both components (EPB and/or CFB see Table 1).

- Stage 4 - Unloading from positive bending (and finish one cycle): In order to close the gap $g_{b}$, a slip must occur in the behaviour curve $\left(F_{T 3_{2}}-\bar{u}_{T 3_{2}}\right)$, Fig. $8(\mathrm{f})$.

Starting the next cycle loading both gaps $\left(g_{t}\right.$ and $\left.g_{b}\right)$ must be closed before to allow the activation of concerned Type. This remark is represented as slips in the behaviour model. Following Loading-Unloading cycles use the same procedure taking care to close previously the gaps.

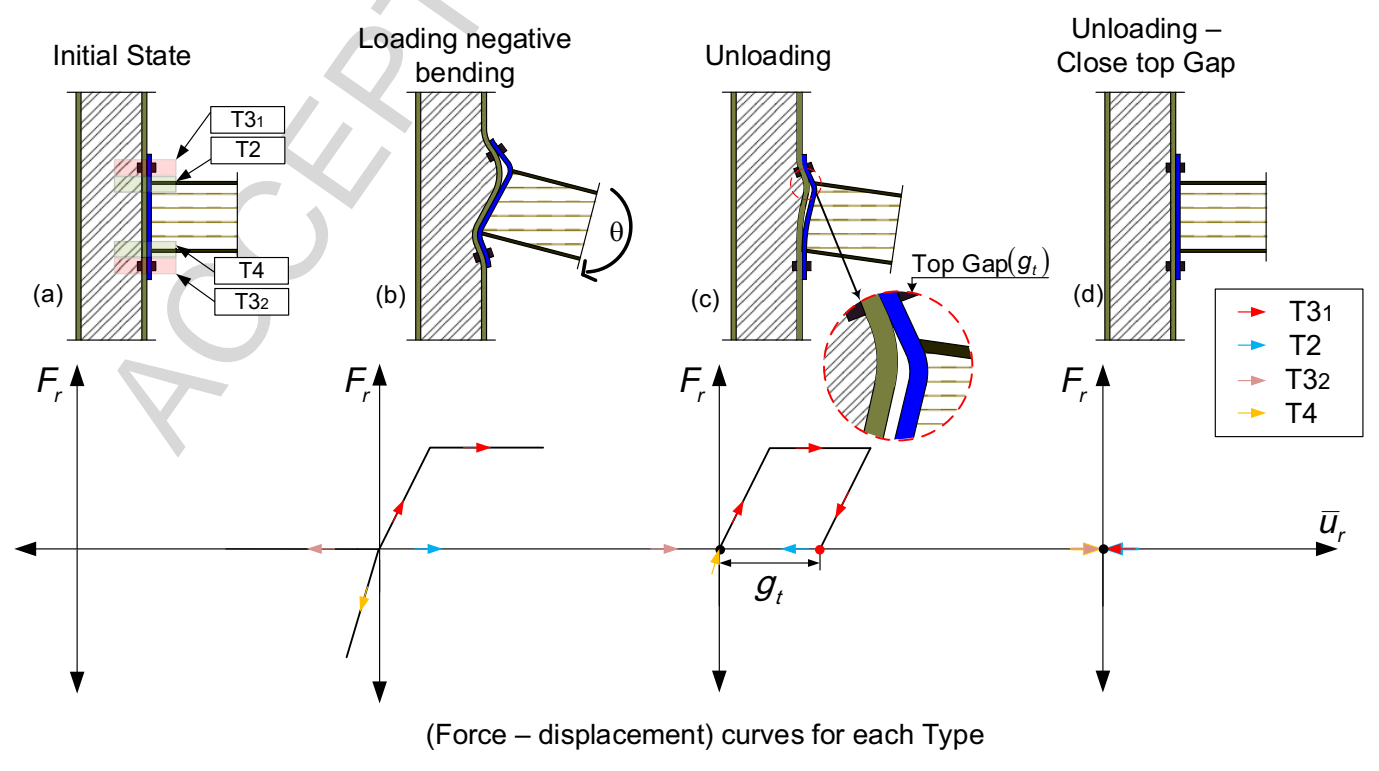

Figure 7: First Loading-Unloading stage (half cycle) 


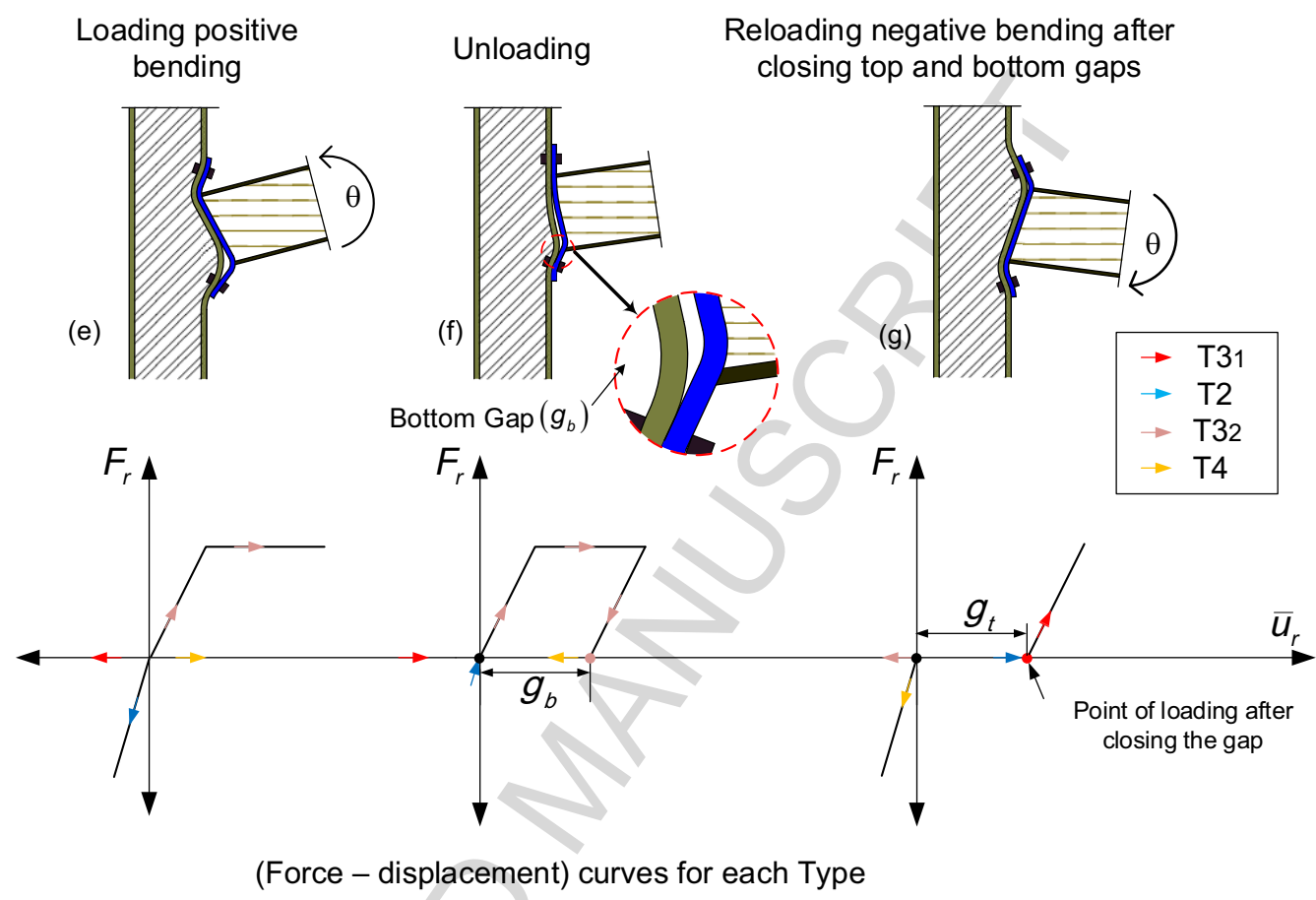

Figure 8: Second Loading-Unloading stage (complete cycle) - Beginning of second cycle

\section{Group of bolt-rows effect}

Cerfontaine [13] proposed to consider the group of bolt-rows effect by the use of a multilinear failure criterion based on the lower bound theorem of limit analysis applied to the joint. In this section, it is proposed to show how to take into account this effect through plasticity modeling.

Assuming normality and associate rules, the plastic flow direction is given by the gradient to the yield surface. Plastic elongation and normal force are evaluated for each bolt-row within a group and the model provides automatically plastic redistribution of this forces within the group of bolt-rows during the loading. It is worth to mention that, the theory that developed for the case of 2 bolt-rows per group is presented in section 5.1 and that one for more than two bolt-rows per group is demonstrated in section 5.2.

\subsection{Group of two bolt-rows}

The proposed formulation is detailed for the case of the group of two bolt-rows $\left(T 3_{1}\right.$ and $\left.T 3_{2}\right)$ (Fig. 9) and will be generalised for groups with more than two bolt-rows.

\subsubsection{Yield surface definition}

The yield criteria depend on three lines (see Fig. 10). Horizontal and vertical yield lines $\left(\Phi_{1}\right.$ and $\left.\Phi_{2}\right)$ correspond individual strength of each bolt-rows and third line $\left(\Phi_{3}\right)$ 


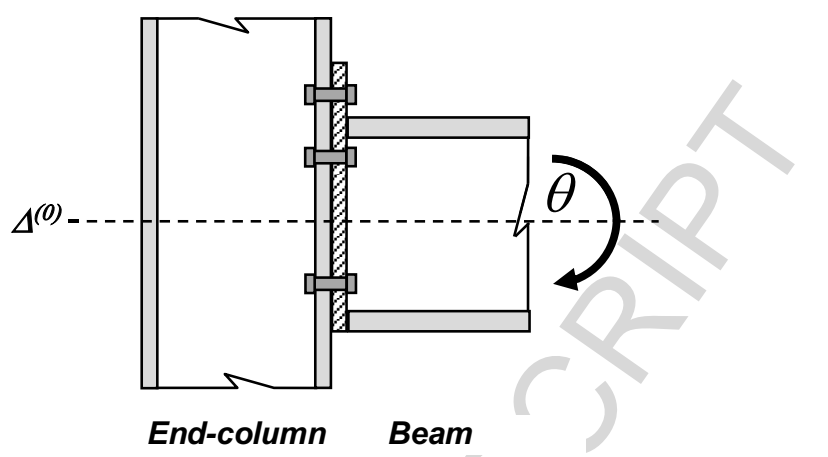

Figure 9: Extended end-plate connection

corresponds to the group strength. Eurocode 3 part 1.8 provides the method to calculate specific strengths. We denote $F_{T 3_{1}, R d}$ and $F_{T 3_{2}, R d}$ : individual strength of the bolt-rows $T 3_{1}$ and $T 3_{2}$ respectively, and $F_{12, R d}$ is the strength of the group of these bolt-rows.

The group effect of two bolt-rows creates five zones that can be distinguished as shown in

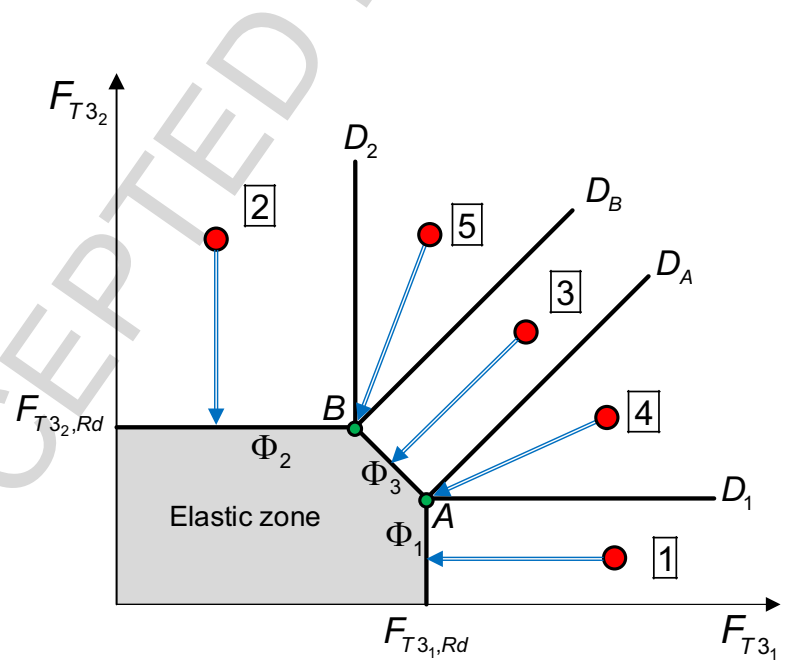

Figure 10: Yield surface for 2 bolt-rows per group

Fig. 10:

- The lines $\left(\Phi_{1}, \Phi_{2}\right.$ and $\left.\Phi_{3}\right)$ that allow to respect the yield criteria are defined by the following equations:

$$
\begin{aligned}
& \Phi_{1}\left(F_{T 3_{1}}, F_{T 3_{1}, R d}\right)=F_{T 3_{1}}-F_{T 3_{1}, R d} \\
& \Phi_{2}\left(F_{T 3_{2}}, F_{T 3_{2}, R d}\right)=F_{T 3_{2}}-F_{T 3_{2}, R d} \\
& \Phi_{3}\left(F_{T 3_{1}}, F_{T 3_{2}}, F_{12, R d}\right)=F_{T 3_{1}}+F_{T 3_{2}}-F_{12, R d}
\end{aligned}
$$

- and the lines that allow to respect normal projections: 
- The lines $D_{A}$ and $D_{B}$ separate respectively the zones (3 and 4$)$ and the zones (3 and $5)$.

- The lines $D_{1}$ and $D_{2}$ separate respectively the zones (1 and 4) and the zones (2 and 5). As-soon-as the trial force is known, appropriate projection is automatically detected. For this aim, firstly the coordinates of the points $A$ and $B$ are obtained using:

$$
\begin{array}{ll}
F_{1 A}=F_{T 3_{1}, R d} & F_{1 B}=F_{12, R d}-F_{T 3_{2}, R d} \\
F_{2 A}=F_{12, R d}-F_{T 3_{1}, R d} & F_{2 B}=F_{T 3_{2}, R d}
\end{array}
$$

Therefore, the lines $\left(D_{A}, D_{B}, D_{1}\right.$ and $\left.D_{2}\right)$ are defined as follows:

$$
\begin{aligned}
& D_{A}\left(F_{T 3_{1}}, F_{T 3_{2}}\right)=F_{T 3_{1}}-F_{T 3_{2}}-\left(2 F_{T 3_{1}, R d}-F_{12, R d}\right) \\
& D_{B}\left(F_{T 3_{1}}, F_{T 3_{2}}\right)=F_{T 3_{1}}-F_{T 3_{2}}+\left(2 F_{T 3_{2}, R d}-F_{12, R d}\right) \\
& D_{1}\left(F_{T 3_{2}}\right)=F_{T 3_{2}}-\left(F_{12, R d}-F_{T 3_{1}, R d}\right) \\
& D_{2}\left(F_{T 3_{1}}\right)=F_{T 3_{1}}-\left(F_{12, R d}-F_{T 3_{2}, R d}\right)
\end{aligned}
$$

Finally, the different zones are defined as follows:

- Elastic zone: The following inequations respect the behaviour of the bolt-rows remain to in the elastic range.

$$
\left\{\begin{array} { l } 
{ \Phi _ { 1 } ( F _ { T 3 _ { 1 } } , F _ { T 3 _ { 1 } , R d } ) \leq 0 } \\
{ \Phi _ { 2 } ( F _ { T 3 _ { 2 } } , F _ { T 3 _ { 2 } , R d } ) \leq 0 } \\
{ \Phi _ { 3 } ( F _ { T 3 _ { 1 } } , F _ { T 3 _ { 2 } } , F _ { 1 2 , R d } ) \leq 0 }
\end{array} \Rightarrow \left\{\begin{array}{l}
\Delta \bar{u}_{T 3_{1}, p}=0 \\
\Delta \bar{u}_{T 3_{2}, p}=0
\end{array}\right.\right.
$$

Herein $\Delta \bar{u}_{T 3_{1}, p}$ and $\Delta \bar{u}_{T 3_{2}, p}$ represent respectively the plastic deformation for the first and the second bolt-rows.

- Zone 1: It is limited by the lines $\Phi_{1}$ and $D_{1}$. The corresponding criterion must respect the following inequations:

$$
\left\{\begin{array} { l } 
{ \Phi _ { 1 } ( F _ { T 3 _ { 1 } } , F _ { T 3 _ { 1 } , R d } ) \geq 0 } \\
{ D _ { 1 } ( F _ { T 3 _ { 2 } } ) \leq 0 }
\end{array} \Rightarrow \left\{\begin{array}{l}
\Delta \bar{u}_{T 3_{1}, p}=\Delta \lambda_{1} \frac{\partial \Phi_{1}}{\partial F_{T 3_{1}}} \\
\Delta \bar{u}_{T 3_{2}, p}=0
\end{array}\right.\right.
$$

- Zone 2: It is limited by the lines $\Phi_{2}$ and $D_{2}$. The corresponding criterion must respect the following inequations:

$$
\left\{\begin{array} { l } 
{ \Phi _ { 2 } ( F _ { T 3 _ { 2 } } , F _ { T 3 _ { 2 } , R d } ) \geq 0 } \\
{ D _ { 2 } ( F _ { T 3 _ { 1 } } ) \leq 0 }
\end{array} \Rightarrow \left\{\begin{array}{l}
\Delta \bar{u}_{T 3_{1}, p}=0 \\
\Delta \bar{u}_{T 3_{2}, p}=\Delta \lambda_{2} \frac{\partial \Phi_{2}}{\partial F_{T 3_{2}}}
\end{array}\right.\right.
$$


- Zone 3: It is limited by the lines $\Phi_{3}, D_{A}$ and $D_{B}$. The corresponding criterion must respect the following inequations:

$$
\left\{\begin{array} { l } 
{ \Phi _ { 3 } ( F _ { T 3 _ { 1 } } , F _ { T 3 _ { 2 } } , F _ { 1 2 , R d } ) \geq 0 } \\
{ D _ { A } ( F _ { T 3 _ { 1 } } , F _ { T 3 _ { 2 } } , F _ { T 3 _ { 1 } , R d } , F _ { 1 2 , R d } ) \leq 0 } \\
{ D _ { B } ( F _ { T 3 _ { 1 } } , F _ { T 3 _ { 2 } } , F _ { T 3 _ { 2 } , R d } , F _ { 1 2 , R d } ) \geq 0 }
\end{array} \quad \Rightarrow \left\{\begin{array}{l}
\Delta \bar{u}_{T 3_{1}, p}=\Delta \lambda_{3} \frac{\partial \Phi_{3}}{\partial F_{T 3_{1}}} \\
\Delta \bar{u}_{T 3_{2}, p}=\Delta \lambda_{3} \frac{\partial \Phi_{3}}{\partial F_{T 3_{2}}}
\end{array}\right.\right.
$$

- Zone 4: The projection reaches directly the point $A$, this zone is limited by the lines $\Phi_{1}$, $\Phi_{3}, D_{A}$ and $D_{1}$. The corresponding criterion must respect the following inequations:

$$
\left\{\begin{array} { l } 
{ \Phi _ { 1 } ( F _ { T 3 _ { 1 } } , F _ { T 3 _ { 1 } , R d } ) > 0 } \\
{ \Phi _ { 3 } ( F _ { T 3 _ { 1 } } , F _ { T 3 _ { 2 } } , F _ { 1 2 , R d } ) > 0 } \\
{ D _ { A } ( F _ { T 3 _ { 1 } } , F _ { T 3 _ { 2 } } , F _ { T 3 _ { 1 } , R d } , F _ { 1 2 , R d } ) > 0 } \\
{ D _ { 1 } ( F _ { T 3 _ { 2 } } ) > 0 }
\end{array} \Rightarrow \left\{\begin{array}{l}
\Delta \bar{u}_{T 3_{1}, p}=\Delta \lambda_{1} \frac{\partial \Phi_{1}}{\partial F_{T 3_{1}}}+\Delta \lambda_{3} \frac{\partial \Phi_{3}}{\partial F_{T 3_{1}}} \\
\Delta \bar{u}_{T 3_{2}, p}=\Delta \lambda_{3} \frac{\partial \Phi_{3}}{\partial F_{T 3_{2}}}
\end{array}\right.\right.
$$

- Zone 5: The projection reaches directly the point $B$, this zone is limited by the lines $\Phi_{2}$, $\Phi_{3}, D_{B}$ and $D_{2}$. The corresponding criterion must respect the following inequations:

$$
\left\{\begin{array} { l } 
{ \Phi _ { 2 } ( F _ { T 3 _ { 2 } } , F _ { T 3 _ { 2 } , R d } ) > 0 } \\
{ \Phi _ { 3 } ( F _ { T 3 _ { 1 } } , F _ { T 3 _ { 2 } } , F _ { 1 2 , R d } ) > 0 } \\
{ D _ { B } ( F _ { T 3 _ { 1 } } , F _ { T 3 _ { 2 } } , F _ { T 3 _ { 2 } , R d } , F _ { 1 2 , R d } ) < 0 } \\
{ D _ { 2 } ( F _ { T 3 _ { 1 } } ) > 0 }
\end{array} \Rightarrow \left\{\begin{array}{l}
\Delta \bar{u}_{T 3_{1}, p}=\Delta \lambda_{3} \frac{\partial \Phi_{3}}{\partial F_{T 3_{1}}} \\
\Delta \bar{u}_{T 3_{2}, p}=\Delta \lambda_{2} \frac{\partial \Phi_{2}}{\partial F_{T 3_{2}}}+\Delta \lambda_{3} \frac{\partial \Phi_{3}}{\partial F_{T 3_{2}}}
\end{array}\right.\right.
$$

\subsubsection{Incremental algorithm of projection}

In accordance with the previous definition of different zones, incremental plasticity algorithm [25] can be established for zone 1 to zone 5:

- Zone 1: In this case, $T 3_{1}$ is in the plastic range:

$$
\Phi_{1}^{n+1}=F_{T 3_{1}}^{n+1}-F_{T 3_{1}, R d}>0
$$

whilst $T 3_{2}$ as-well-as the group of $\left(T 3_{1}\right.$ and $\left.T 3_{2}\right)$ are in the elastic range:

$$
\begin{aligned}
& \Phi_{2}^{n+1}=F_{T 3_{2}}^{n+1}-F_{T 3_{2}, R d} \leq 0 \Rightarrow k_{T 3_{2}}^{n+1}=k_{e 2} \\
& \Phi_{3}^{n+1}=F_{T 3_{1}}^{n+1}+F_{T 3_{2}}^{n+1}-F_{12, R d} \leq 0
\end{aligned}
$$

Herein $k_{e 2}$ is the elastic stiffness of $T 3_{2}$, Eq. (2).

The current force in the $T 3_{1}$ at $(\mathrm{n}+1)$ increment is given as:

$$
\begin{aligned}
F_{T 3_{1}}^{n+1} & =k_{e 1}\left(\bar{u}_{T 3_{1}}^{n+1}-\bar{u}_{T 3_{1}, p}^{n+1}\right) \\
& =F_{T 3_{1}, \text { trial }}^{n+1}-k_{e 1} \Delta \lambda_{1}
\end{aligned}
$$

where $k_{e 1}$ is the elastic stiffness of $T 3_{1}$, Eq. (2).

The yield function becomes:

$$
\Phi_{1}^{n+1}=\left(F_{T 3_{1}, t r i a l}^{n+1}-k_{e 1} \Delta \lambda_{1}\right)-F_{T 3_{1}, R d}=0
$$


- The increment of plastic multiplier:

$$
\Delta \lambda_{1}=\frac{\Phi_{1, \text { trial }}^{n+1}}{k_{e 1}}
$$

- The tangent stiffness

Derivation of (24) gives:

$$
k_{T 3_{1}}^{n+1}=\frac{\partial F_{T 3_{1}}^{n+1}}{\partial \bar{u}_{T 3_{1}}^{n+1}}=\frac{\partial F_{T 3_{1}, \text { trial }}^{n+1}}{\partial \bar{u}_{T 3_{1}}^{n+1}}-\frac{\partial \Delta \lambda_{1}}{\partial \bar{u}_{T 3_{1}}^{n+1}} k_{e 1}
$$

Substituting Eq. (26) into (27) leads to:

$$
k_{T 3_{1}}^{n+1}=0
$$

- Zone 2: In this case, $T 3_{1}$ and the group of $\left(T 3_{1}\right.$ and $\left.T 3_{2}\right)$ are in the elastic domain:

$$
\begin{aligned}
& \Phi_{1}^{n+1}=F_{T 3_{1}}^{n+1}-F_{T 3_{1}, R d} \leq 0 \Rightarrow k_{T 3_{1}}^{n+1}=k_{e 1} \\
& \Phi_{3}^{n+1}=F_{T 3_{1}}^{n+1}+F_{T 3_{2}}^{n+1}-F_{12, R d} \leq 0
\end{aligned}
$$

whilst $T 3_{2}$ is in the plastic range:

$$
\Phi_{2}^{n+1}=F_{T 3_{2}}^{n+1}-F_{T 3_{2}, R d}>0
$$

The same procedure as for the first bolt-row is followed for the second bolt-row, therefore we can define

- The increment of plastic multiplier:

$$
\Delta \lambda_{2}=\frac{\Phi_{2, \text { trial }}^{n+1}}{k_{e 2}}
$$

- The tangent stiffness

$$
k_{T 3_{2}}^{n+1}=0
$$

- Zone 3: The group criterion is activated:

$$
\Phi_{3}^{n+1}=F_{T 3_{1}}^{n+1}+F_{T 3_{2}}^{n+1}-F_{12, R d}>0
$$

Trial force of the group $\left(T 3_{1}\right.$ and $\left.T 3_{2}\right)$

$$
F_{12, \text { trial }}^{n+1}=F_{T 3_{1}, \text { trial }}^{n+1}+F_{T 3_{2}, \text { trial }}^{n+1}
$$

and corrected force is:

$$
\begin{aligned}
F_{12}^{n+1} & =F_{T 3_{1}}^{n+1}+F_{T 3_{2}}^{n+1} \\
& =k_{e 1}\left(\bar{u}_{T 3_{1}}^{n+1}-\bar{u}_{T 3_{1}, p}^{n+1}\right)+k_{e 2}\left(\bar{u}_{T 3_{2}}^{n+1}-\bar{u}_{T 3_{2}, p}^{n+1}\right) \\
& \Rightarrow F_{12}^{n+1}=F_{12, \text { trial }}^{n+1}-\Delta \lambda_{3}\left(k_{e 1}+k_{e 2}\right) \\
& 14
\end{aligned}
$$


where: $F_{12, \text { trial }}^{n+1}=F_{T 3_{1}, \text { trial }}^{n+1}+F_{T 3_{2}, \text { trial }}^{n+1}$

The yield function can be written as follows:

$$
\Phi_{3}^{n+1}=F_{12, \text { Trial }}^{n+1}-\Delta \lambda_{3}\left(k_{e 1}+k_{e 2}\right)-F_{12, R d}=0
$$

- The increment of plastic multiplier:

$$
\Delta \lambda_{3}=\frac{\Phi_{3, \text { Trial }}^{n+1}}{k_{e 1}+k_{e 2}}
$$

where: $\Phi_{3, \text { trial }}^{n+1}=F_{T 3_{1}, \text { trial }}^{n+1}+F_{T 3_{2}, \text { trial }}^{n+1}-F_{12, R d}$

- The tangent stiffness:

i. Tangent stiffness for $T 3_{1}$ is given by:

$$
k_{T 3_{1}}^{n+1}=\frac{\partial F_{T 3_{1}}^{n+1}}{\partial \bar{u}_{T 3_{1}}^{n+1}}=\frac{\partial F_{T 3_{1}, t r i a l}^{n+1}}{\partial \bar{u}_{T 3_{1}}^{n+1}}-k_{e 1} \frac{\partial\left(\Delta \lambda_{3}\right)}{\partial \bar{u}_{T 3_{1}}^{n+1}}=\frac{k_{e 1} k_{e 2}}{k_{e 1}+k_{e 2}}
$$

ii. Tangent stiffness for $T 3_{2}$ is given by:

$$
k_{T 3_{2}}^{n+1}=\frac{\partial F_{T 3_{2}}^{n+1}}{\partial \bar{u}_{T 3_{2}}^{n+1}}=\frac{\partial F_{T 3_{2}, \text { trial }}^{n+1}}{\partial \bar{u}_{T 3_{2}}^{n+1}}-k_{e 2} \frac{\partial\left(\Delta \lambda_{3}\right)}{\partial \bar{u}_{T 3_{2}}^{n+1}}=\frac{k_{e 1} k_{e 2}}{k_{e 1}+k_{e 2}}
$$

- Zone 4: In this case we have:

$$
\begin{aligned}
& \Phi_{1}^{n+1}=F_{T 3_{1}}^{n+1}-F_{T 3_{1}, R d}>0 \\
& \Phi_{3}^{n+1}=F_{T 3_{1}}^{n+1}+F_{T 3_{2}}^{n+1}-F_{12, R d}>0
\end{aligned}
$$

The yield function is written as:

$$
\begin{aligned}
\Phi_{1}^{n+1} & =F_{T 3_{1}, \text { trial }}^{n+1}-k_{e 1} \Delta \lambda_{1}-k_{e 1} \Delta \lambda_{3}-F_{T 3_{1}, R d}=0 \\
& \Rightarrow k_{e 1} \Delta \lambda_{1}+k_{e 1} \Delta \lambda_{3}=\Phi_{1, \text { trial }}^{n+1}
\end{aligned}
$$

On the other side, the yield surface function $\Phi_{3}$ can be defined as follows:

$$
\begin{aligned}
\Phi_{3}^{n+1} & =F_{T 3_{1}, \text { trial }}^{n+1}-k_{e 1} \Delta \lambda_{1}-k_{e 1} \Delta \lambda_{3}+F_{T 3_{2}, \text { trial }}^{n+1}-k_{e 2} \Delta \lambda_{3}-F_{12, R d} \\
& \Rightarrow k_{e 1} \Delta \lambda_{1}+\Delta \lambda_{3}\left(k_{e 1}+k_{e 2}\right)=\Phi_{3, \text { trial }}^{n+1}
\end{aligned}
$$

Combining the last equations of (40) and (41), we obtain:

$$
\left[\begin{array}{cc}
k_{e 1} & k_{e 1} \\
k_{e 1} & k_{e 1}+k_{e 2}
\end{array}\right]\left\{\begin{array}{c}
\Delta \lambda_{1} \\
\Delta \lambda_{3}
\end{array}\right\}=\left\{\begin{array}{l}
\Phi_{1, t \text { trial }}^{n+1} \\
\Phi_{3, \text { trial }}^{n+1}
\end{array}\right\}
$$

Solving (42) leads to: 
- Plastic multipliers:

i.

$$
\Delta \lambda_{1}=\frac{\Phi_{1, \text { trial }}^{n+1}\left(k_{e 1}+k_{e 2}\right)-\Phi_{3, \text { trial }}^{n+1} k_{e 1}}{k_{e 1} k_{e 2}}
$$

ii.

$$
\Delta \lambda_{3}=\frac{\Phi_{3, \text { trial }}^{n+1}-\Phi_{1, \text { trial }}^{n+1}}{k_{e 2}}
$$

- Tangent stiffness:

i. Tangent stiffness for $T 3_{1}$ is defined by:

$$
k_{T 3_{1}}^{n+1}=\frac{\partial F_{T 3_{1}}^{n+1}}{\partial \bar{u}_{T 3_{1}}^{n+1}}=\frac{\partial F_{T 3_{1}, \text { trial }}^{n+1}}{\partial \bar{u}_{T 3_{1}}^{n+1}}-k_{e 1} \frac{\partial\left(\Delta \lambda_{3}\right)}{\partial \bar{u}_{T 3_{1}}^{n+1}}-k_{e 1} \frac{\partial\left(\Delta \lambda_{1}\right)}{\partial \bar{u}_{T 3_{1}}^{n+1}}
$$

where

$$
\begin{aligned}
& k_{e 1} \frac{\partial\left(\Delta \lambda_{1}\right)}{\partial \bar{u}_{T 3_{1}}^{n+1}}=k_{e 1} \\
& k_{e 1} \frac{\partial\left(\Delta \lambda_{3}\right)}{\partial \bar{u}_{T 3_{1}}^{n+1}}=0
\end{aligned}
$$

Replace (46) into (45) gives

$$
k_{T 31}^{n+1}=0
$$

ii. Tangent stiffness for $T 3_{2}$ is defined by:

$$
k_{T 3_{2}}^{n+1}=\frac{\partial F_{12}^{n+1}}{\partial \bar{u}_{T 3_{2}}^{n+1}}=\frac{\partial F_{T 3_{2}, \text { trial }}^{n+1}}{\partial \bar{u}_{T 3_{2}}^{n+1}}-k_{e 2} \frac{\partial\left(\Delta \lambda_{3}\right)}{\partial \bar{u}_{T 3_{2}}^{n+1}}
$$

where

$$
k_{e 2} \frac{\partial\left(\Delta \lambda_{3}\right)}{\partial \bar{u}_{T 3_{2}}^{n+1}}=k_{e 2}
$$

Combining (48) and (49) gives

$$
k_{T 3_{2}}^{n+1}=0
$$

- Zone 5:

In this case we have two activated yield surfaces: one concerns $T 3_{2}$ and the other corresponds to the group of $\left(T 3_{1}\right.$ and $\left.T 3_{2}\right)$.

$$
\begin{aligned}
& \Phi_{2}^{n+1}=F_{T 3_{2}}^{n+1}-F_{T 3_{2}, R d}>0 \\
& \Phi_{3}^{n+1}=F_{T 3_{1}}^{n+1}+F_{T 3_{2}}^{n+1}-F_{12, R d}>0
\end{aligned}
$$


i. The increment of plastic multiplier can be defined by:

$$
\left[\begin{array}{cc}
k_{e 2} & k_{e 2} \\
k_{e 2} & k_{e 1}+k_{e 2}
\end{array}\right]\left\{\begin{array}{c}
\Delta \lambda_{2} \\
\Delta \lambda_{3}
\end{array}\right\}=\left\{\begin{array}{l}
\Phi_{2, \text { trial }}^{n+1} \\
\Phi_{3, \text { trial }}^{n+1}
\end{array}\right\}
$$

ii. The tangent stiffnesses of the $\left(T 3_{1}\right.$ and $\left.T 3_{2}\right)$ are:

$$
\begin{aligned}
& k_{T 3_{1}}^{n+1}=0 \\
& k_{T 3_{2}}^{n+1}=0
\end{aligned}
$$

\subsection{General formulation for the group effect criterion}

- The general formulation for the bolt-rows interaction criterion can be written as follows:

$$
F_{T 3_{q}}+F_{T 3_{s}} \leq \operatorname{Min}\left[F_{q s, R d},\left(F_{k s, R d}-\sum_{i=k}^{q-1} F_{T 3_{i}}\right)_{k=1, . .,(q-1)}\right]
$$

where $q=2, \ldots m-1$; and $s=q+1, \ldots . ., m$, in which $m$ is the total number of the bolt-rows in the joint. $F_{q s}$ and $F_{k s}$ are the group resistances including the bolt-rows from ( $q$ to $s)$ or $(k$ to $s)$, respectively.

- Example of a group of three bolt-rows: In the aim to take into account the effect of three bolt-rows (Fig. 11), Successive group effects of two bolt-rows are proposed. The steps of the group effect occurrence in the case of positive bending can be described. The method remains available in case of negative bending.

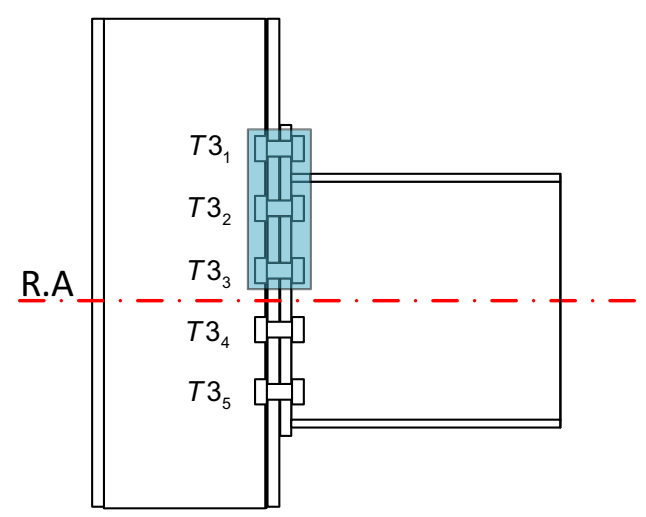

Figure 11: End-plate connection with several bolt-rows

It can be distinguished:

- Group effect $1\left(T 3_{1}, T 3_{2}\right)$. 
- Group effect $2\left(T 3_{2}, T 3_{3}\right)$.

According to EC3, individual and group resistances can be easily obtained and denoted as follows:

- Individual: $\left(F_{T 3_{1}, R d}, F_{T 3_{2}, R d}\right)$.

- Group 1: $\left(F_{12, R d}\right)$.

- Group 2: $\left(F_{23, R d}\right)$.

In case of negative bending:

- Group effect 1 is controlled by following criterion:

$$
F_{T 3_{1}}+F_{T 3_{2}} \leq F_{12, R d}
$$

- Group effect 2 is controlled by the combination of both following criteria:

$$
F_{T 3_{2}}+F_{T 3_{3}} \leq F_{23, R d} \quad \text { and } \quad F_{T 3_{1}}+F_{T 3_{2}}+F_{T 3_{3}} \leq F_{13, R d}
$$

The first equation of Eqs. (56) corresponds to the group effect of the two bolt-rows $T 3_{2}$ and $T 3_{3}$ and the second equation corresponds the group effect of the three bolt-rows $T 3_{1}, T 3_{2}$ and $T 3_{3}$. The combination of these equations leads to the following criterion:

$$
F_{T 3_{2}}+F_{T 3_{3}} \leq \operatorname{Min}\left[F_{23, R d},\left(F_{13, R d}-F_{T 3_{1}}\right)\right]
$$

\section{Numerical applications}

Two numerical simulations were performed to highlight both improvements proposed to the joint response obtained by the component-based model. The first one concerns the gap effect and the second one concerns the group effect.

\subsection{Example for the gap effect}

The simple example of two bolt-rows (Fig. 12) is used to investigate the influence of the gap effect on the joint behavior. Two cycles of rotations are applied to this joint according to the diagram given in Fig. 13. Corresponding mechanical model is given in Fig. 14. The steel grade that adopted is S355 and the Young's Modulus is $210 \mathrm{GPa}$. This example has been solved using proposed mechanical model analysis and 3D finite element modelling. 


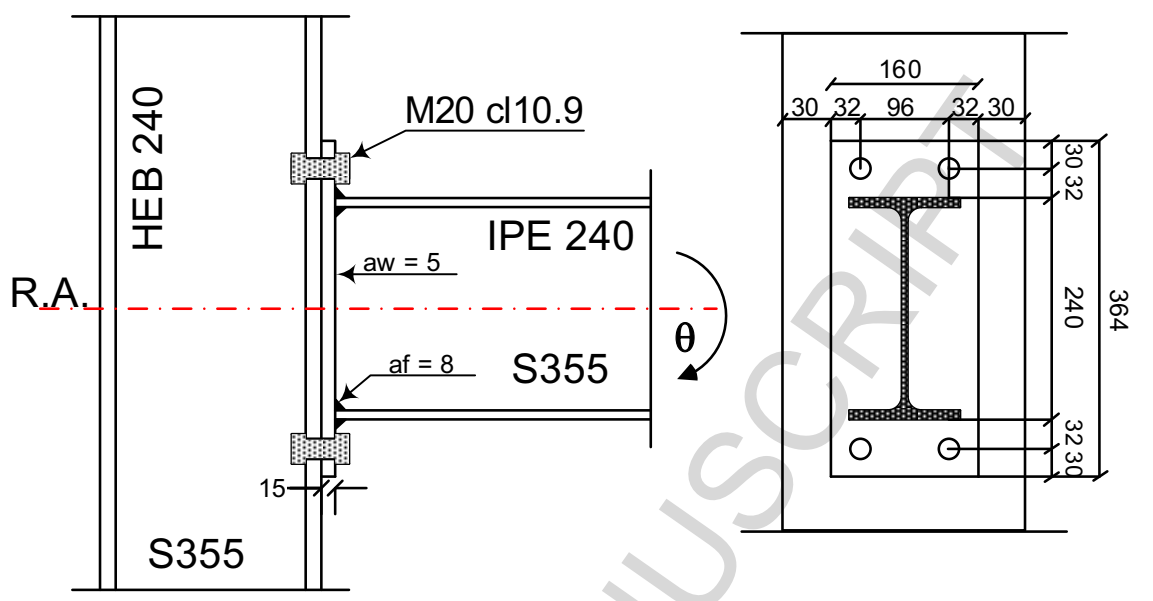

Figure 12: Example for the gap effect

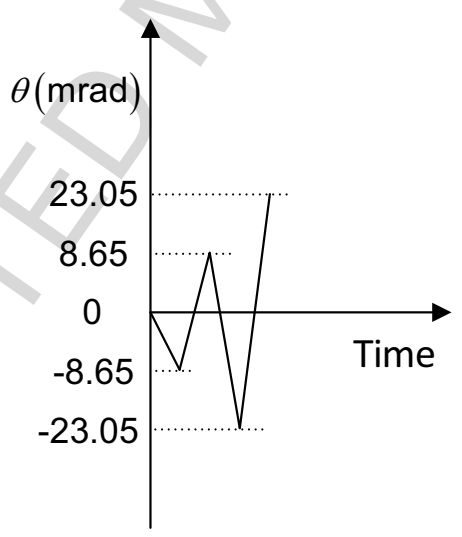

Figure 13: Cyclic loading history

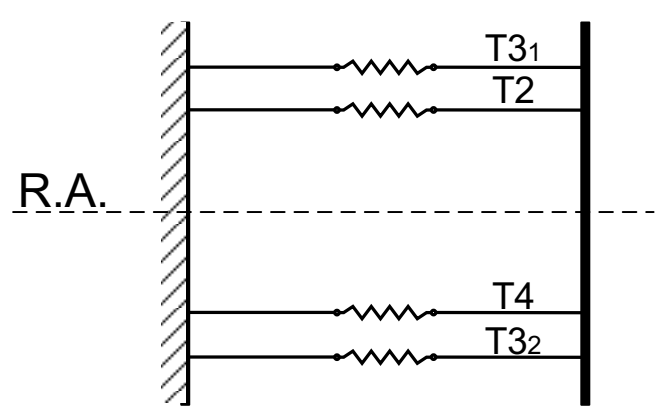

Figure 14: Mechanical model 
Table 2: Initial stiffness and resistance force $(\mathrm{kN} / \mathrm{mm}$ and $\mathrm{kN})$

\begin{tabular}{|c|c|c|c|c|}
\hline \multirow{2}{*}{ Component } & \multicolumn{2}{|c|}{$T 3_{1}$ and $T 3_{2}$} & \multicolumn{2}{c|}{$\mathrm{T} 2$ and T4 } \\
\cline { 2 - 5 } & $F_{R d}$ & $k_{i n i}$ & $F_{R d}$ & $k_{i n i}$ \\
\hline CFB & 352 & 8498 & - & - \\
\hline CWT & 508 & 1475 & - & - \\
\hline EPB & $\mathbf{2 5 8}$ & 4221 & - & - \\
\hline CWC & - & - & 642 & 2150 \\
\hline BFWC & - & - & $\mathbf{5 6 5}$ & $\infty$ \\
\hline BT & 441 & 1630 & - & - \\
\hline
\end{tabular}

\subsubsection{Proposed mechanical model analysis}

In this section the proposed mechanical model will be used to capture the cyclic response of the connection. It is worth to point out that the strength of equivalent Type spring is obtained as the minimum of the strengths of included components (highlighted values in Table 2).

For each component within the joint, material hardening has been considered very light $\left(k_{e q, r} / 1000\right)$ but not equal to zero. In accordance with the cyclic loading history (Fig. 13), the (Moment - Rotation) curve obtained as the response of the joint behavior is given in Fig. 15. It appears clearly that the gaps obtained at both top and bottom levels of the joint generate slipping at both sides of the zero-rotation axis of the curve (horizontal dashed arrows). Alternatively between top and bottom bolt-rows, the gap obtained by the tension of the top bolt-row for example, must be first recovered before beginning the tension at the bottom bolt-row. The proposed algorithm follows these sequences very rigorously in order to insure an accurate solution of the proposed model (the index $t$ corresponds to the $T 3_{1}$ in tension and the index $b$ to the $T 3_{2}$ in tension).

- First loading cycle $(-8.65 \mathrm{mrad} \leq \theta \leq 8.65 \mathrm{mrad})$ :

$\begin{array}{ll}\left(O-A_{t}-B_{t}\right) & \text { Loading in negative bending }(1-2) \\ \left(B_{t}-C_{t}\right) & \text { Unloading }(3) \\ \left(C_{t}-O\right) & \text { Slipping }(4) \\ \left(O-A_{b}-B_{b}\right) & \text { Loading in positive bending } \\ \left(B_{b}-C_{b}\right) & \text { Unloading } \\ \left(C_{b}-O\right) & \text { Slipping }\end{array}$

- Second loading cycle $(-23.05 \mathrm{mrad} \leq \theta \leq 23.05 \mathrm{mrad})$ :

$\begin{array}{ll}\left(C_{t}-B_{t}-D_{t}\right) & \text { Reloading in negative bending }(5-6) \\ \left(D_{t}-E_{t}\right) & \text { Unloading }(7) \\ \left(E_{t}-C_{t}-O-C_{b}\right) & \text { Slipping } \\ \left(C_{b}-B_{b}-D_{b}\right) & \text { Reloading in positive bending } \\ \left(D_{b}-E_{b}\right) & \text { Unloading }\end{array}$




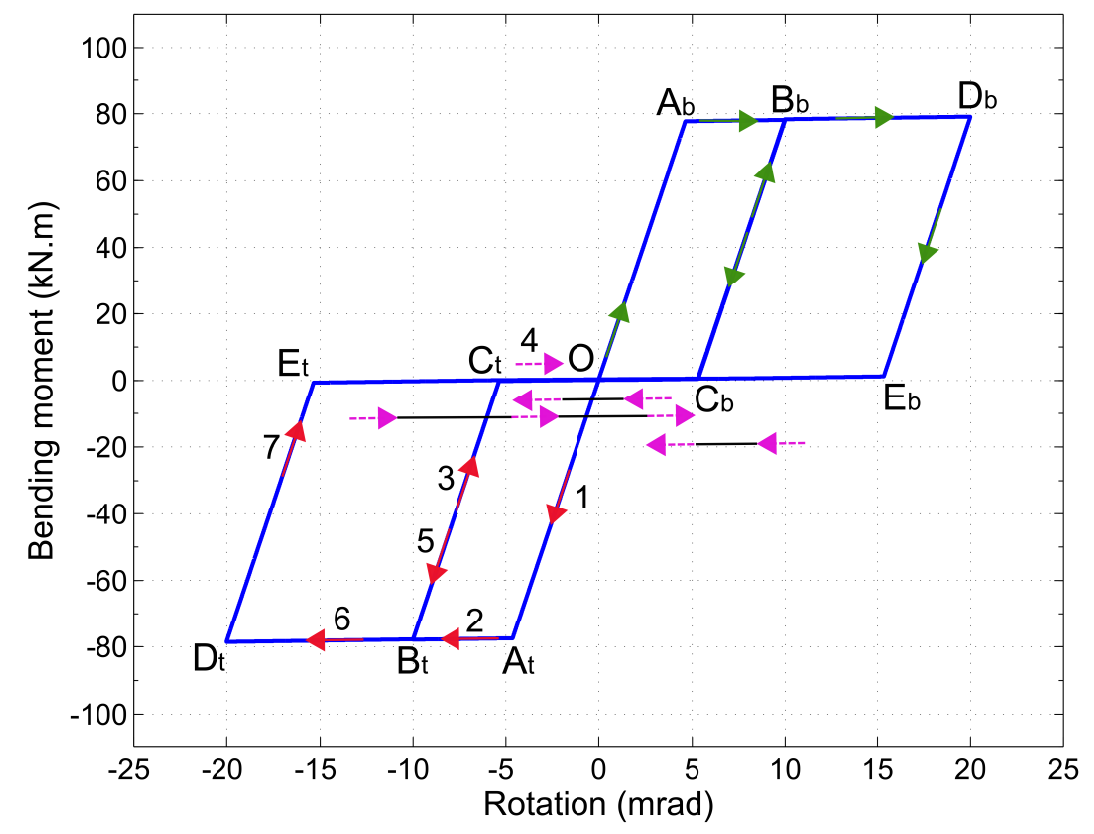

Figure 15: Moment vs. Rotation curve

After each load cycle, the plastic deformation of the components within each equivalent spring are cumulated. At the end of the unloading stage, permanent deformation defining the so-called gap needs to be closed to allow the activation of the others rows. In accordance with Fig. 15, following values of couples (Moment - Rotation) of the joints are obtained when the top bolt-row is active (same results when the bottom bolt-row is active because of symmetry):

- First loading cycle $(-10 \mathrm{mrad} \leq \theta \leq 10 \mathrm{mrad})$ :
$\left(O-A_{t}-B_{t}\right)$
$(0-0),(77.47-4.64),(77.88-10)$
$\left(B_{t}-C_{t}\right)$
$(77.88-10),(0-5.36)$
$\left(C_{t}-O\right)$
$(0-5.36),(0-0)$

- Second loading cycle $(-20 \mathrm{mrad} \leq \theta \leq 20 \mathrm{mrad})$ :

$$
\begin{array}{ll}
\left(O-C_{t}\right) & (0-0),(0-5.36) \\
\left(C_{t}-B_{t}-D_{t}\right) & (0-5.36),(77.88-10),(78.55-20) \\
\left(D_{t}-E_{t}\right) & (78.55-20),(0-15.34) \\
\left(E_{t}-O\right) & (0-15.34)-(0-0)
\end{array}
$$

It worth to precise that the couple of springs $\left(T 3_{1}-T 4\right)$ are active in same time and $\left(T 3_{2}\right.$ - T2) also, and both couples are active alternatively (Fig. 16); therefore:

- Negative displacement obtained in the spring T4 (bottom beam-flange row) is due to a compression force while the tension is active in the spring $T 3_{1}$ (top bolt-row). 
- Negative displacement obtained in the spring $T 3_{2}$ (bottom bolt-row) is due to a slipping (the spring does not support any compression force) while the positive displacement obtained in the spring $T_{2}$ (top beam-flange row) is also a slipping (this row does not support any tension).

It is clear that the behavior of each equivalent spring "Type" (Fig. 16) follows both sleeps occurred during these two loading cycles. The slipping values obtained from these curves are:

- $\left(C_{t}-O\right)=1.208 \mathrm{~mm}$

- $\left(E_{t}-O\right)=5.056 \mathrm{~mm}$

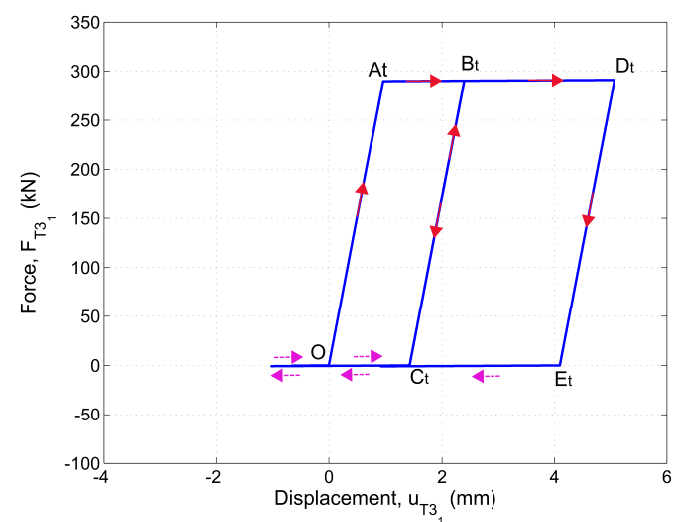

(a) Top bolt-row $T 3_{1}$

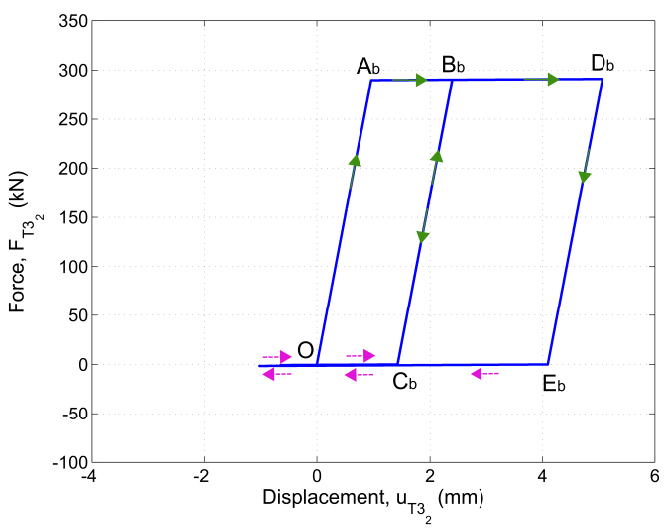

(c) Bottom bolt-row $T 3_{2}$

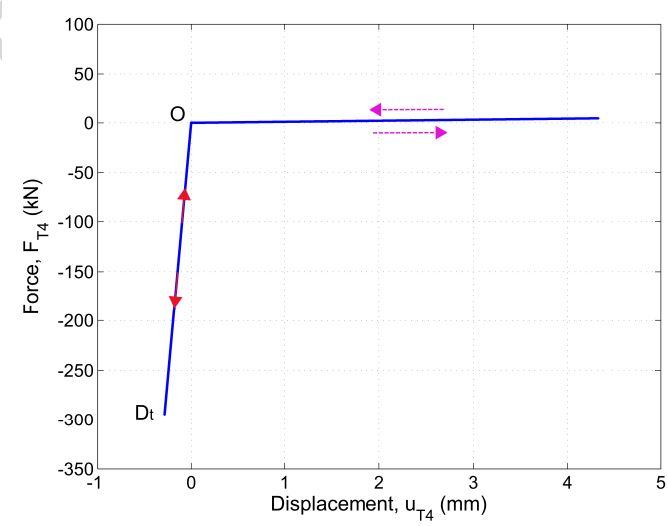

(b) Bottom beam-flange row T4

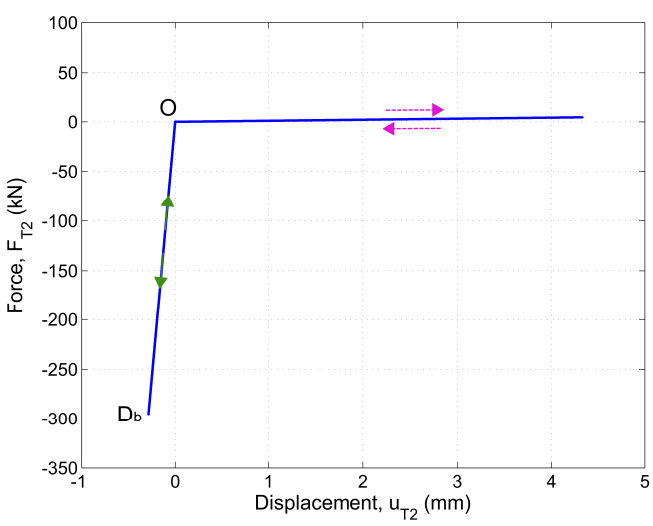

(d) Top beam-flange row $T 2$

Figure 16: Force-displacement curves for each row of the joint 


\subsubsection{D Finite element modelling}

In order to validate our proposed mechanical model, a $3 \mathrm{D}$ model of the previous endplate connection, Fig. 12, is investigated with the finite element codes ABAQUS. The three-dimensional solid element type C3D8R have been used. The contact element between the end-plate and the column flange surfaces as well as between the end-plate, the column flange and the bolts surface are used with friction coefficient of 0.3. All the nodes of the top and bottom section of the column are restrained in all directions. In order to achieve reliable results, a fine mesh was employed in the contact zone as shown in the general view of the mesh pattern for the connection, Fig. 17.

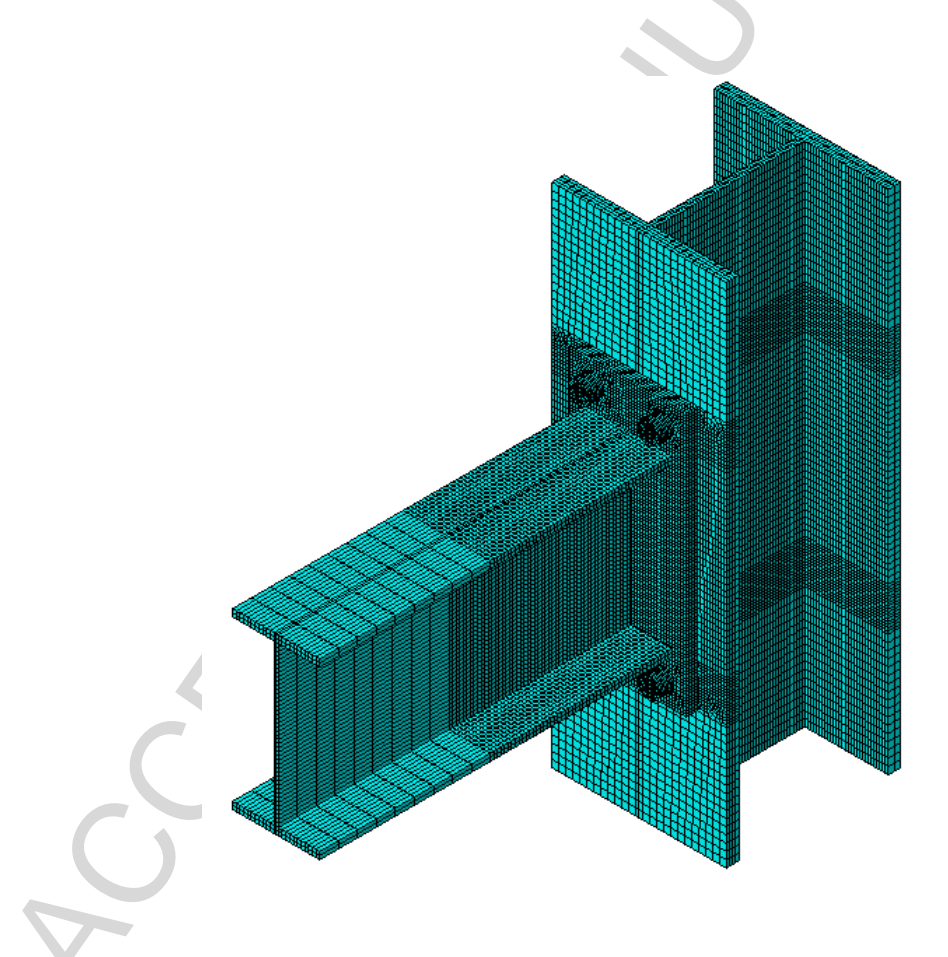

Figure 17: Mesh pattern of the finite element model

In the other hand, the steel material, type S355, for the components involved the creation of the gap; Column-flange, end-plate and bolts, is considered as ductile and behave as elasticperfectly plastic. Whilst, the other components have an elastic behavior.

In this analysis displacement control was applied, rotation, to a rigid surface at the end of the beam. The applied rotation was cyclic and controlled by amplitude function.

- Results and discussions The moment-rotation curve results from FE model is compared to the mechanical model response developed in section 3 and implemented in MATLAB, the two responses are demonstrated in Fig. 18. It can be observed that the connection response from the developed mechanical model has a good agreement with that from 3D FE mainly in the initial stiffness and moment resistance. It is worth to 


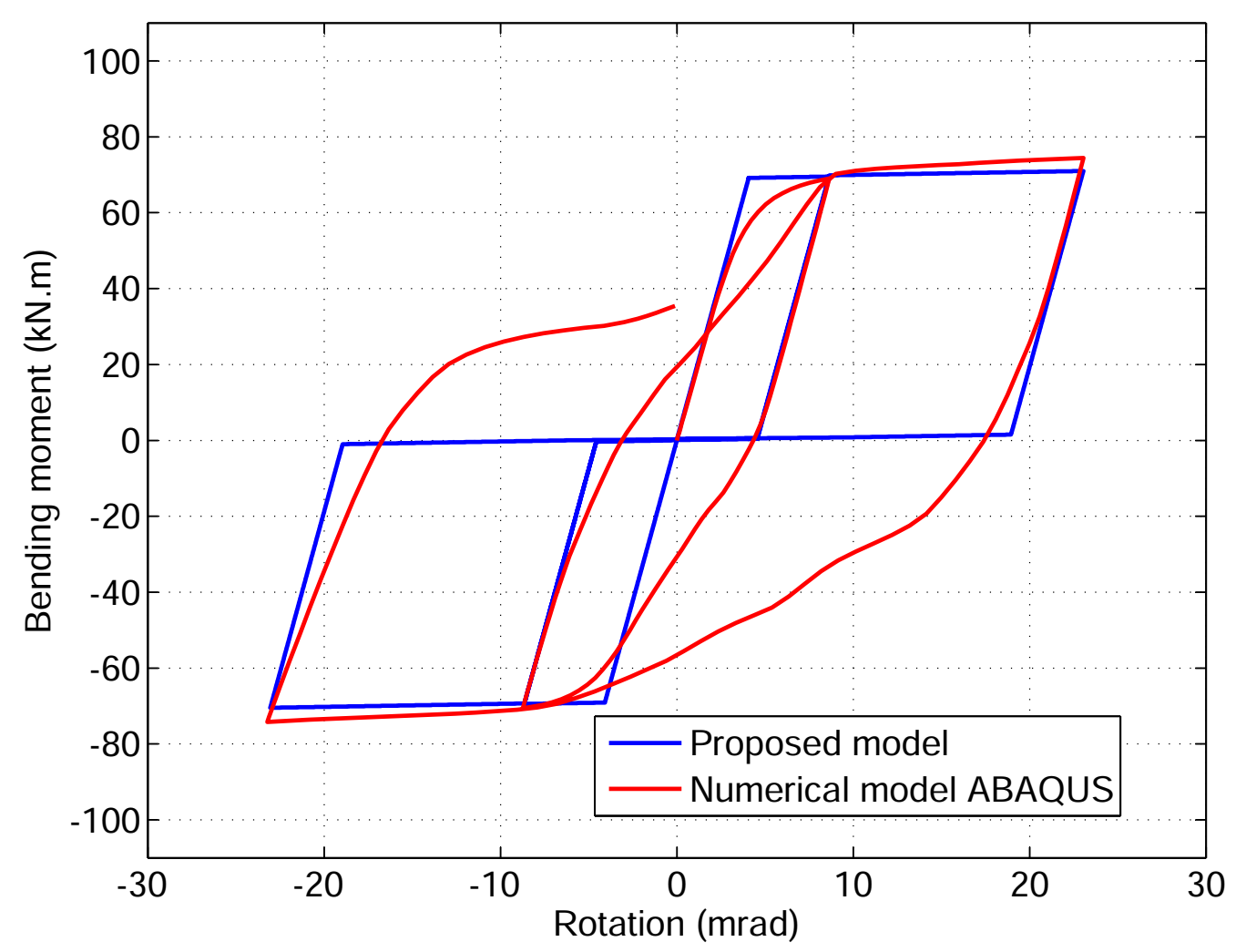

Figure 18: Moment vs. rotation curves 
mention that in this example there is no group effect because the two bolt-rows do not work together under bending moment.

The creation of the gap is very clear in the 3D finite element simulation and this separation, as expected, comes from plastic deformation of the end-plate in bending (see Fig. 19).

The gap effect is demonstrated in the moment-rotation curve as the following:

i In the proposed model a slipping phenomenon is adopted on the force-displacement curve of the equivalent spring therefore, the benching-effect is significant in the cyclic response.

ii For 3D FE model the benching -effect is not significant as in the response of the proposed model, in contrast a degradation of the stiffness is observed during closing the gap.
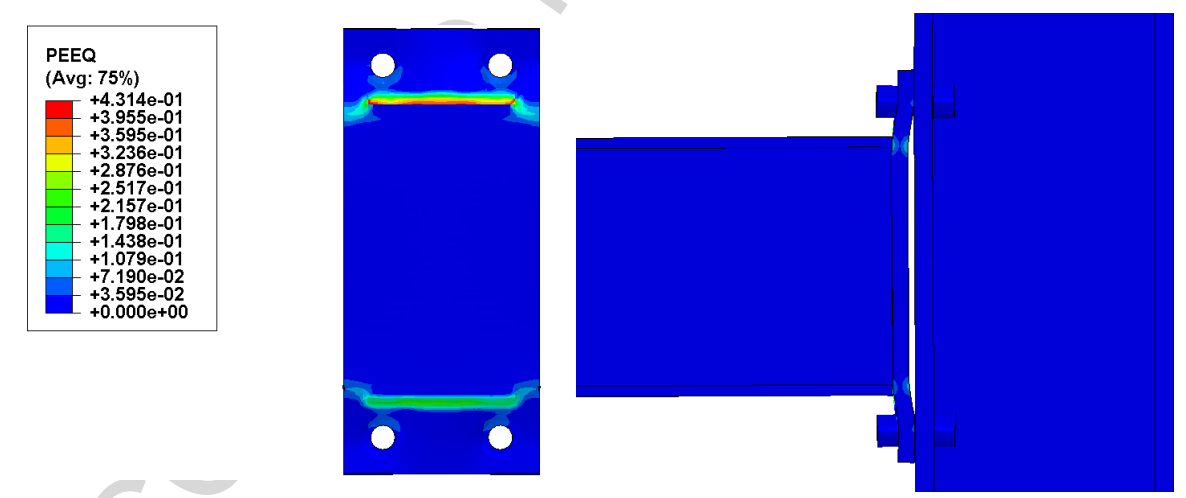

Figure 19: Plastic deformation in the connection at the end of the 3D FE simulation

\subsection{Example for the group effect}

The following application concerns an example of a semi-rigid connection that has been analyzed by Cerfontaine [13] (Fig. 20). This example consists of an IPE600 steel beam connected to a HEB400 steel column towards an end-plate with 5 bolt-rows denoted $T 3_{i}$ $(i=1, . ., 5)$. Table 3 summarizes the resistances and equivalent stiffnesses of each individual and group of bolt-rows. In addition, the same data are given for the Types T2 and T4 located at the top and the bottom beam flange levels, respectively. According to the Eq. (54) (where $m=5$ ) the yield surface criterion for different combination of group of bolt-rows are obtained and reported in Table 4. Two calculations have been performed:

- Calculation 1: The data given in Table 3 are the same as those of Cerfontaine [13]. In this conditions, it appears that no group effect is activated (Fig. 21 ). 


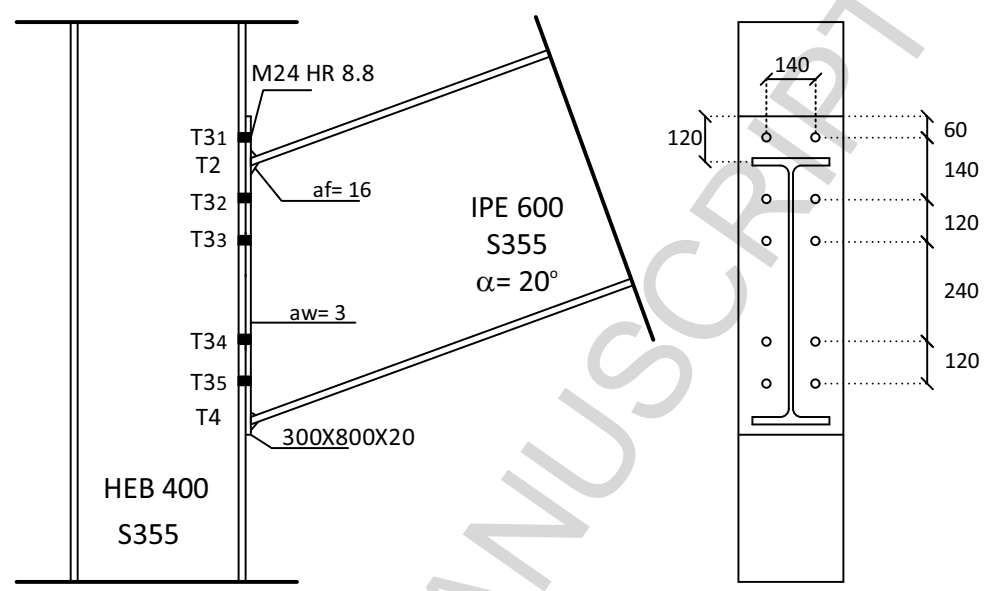

Figure 20: Bolted end-plate configuration

Table 3: Types and Groupes characterisation

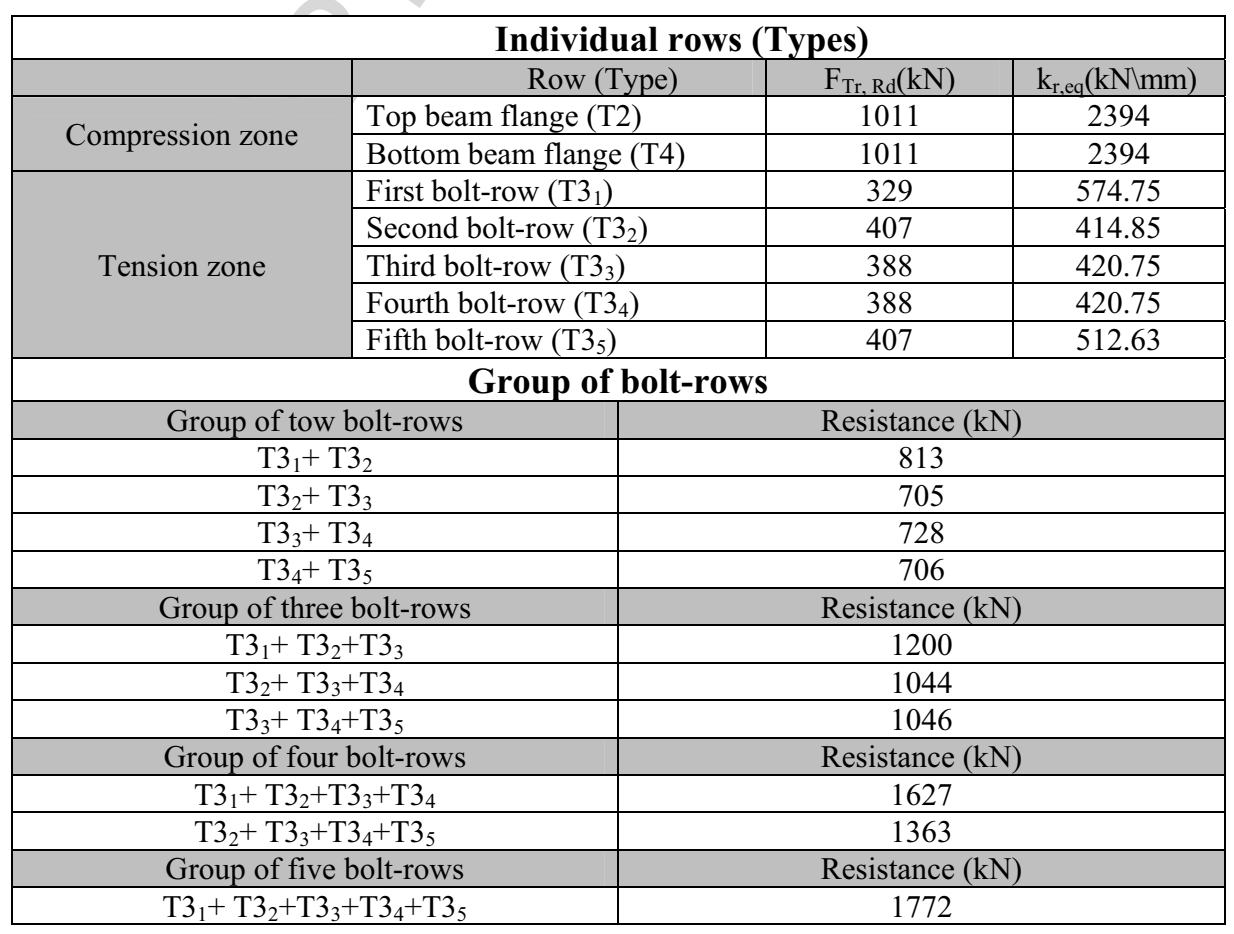


- Calculation 2: In order to activate the group effects, it is proposed to increase (arbitrary) the resistance of Type $T 4$ from $1011 k N$ to $1500 k N$ (Fig. 22).

Table 4: Yield surface criterion for this example(5 bolt-rows)

\begin{tabular}{|c|c|c|}
\hline$q$ & $s$ & $F_{T 3_{q}}+F_{T 3_{s}} \leq$ \\
\hline 2 & 3 & $\operatorname{Min}\left[F_{23, R d},\left(F_{13, R d}-F_{T 3_{1}}\right)\right]$ \\
\hline 3 & 4 & $\operatorname{Min}\left[F_{34, R d},\left(F_{14, R d}-F_{T 3_{1}}-F_{T 3_{2}}\right),\left(F_{24, R d}-F_{T 3_{2}}\right)\right]$ \\
\hline 4 & 5 & $\operatorname{Min}\left[F_{45, R d},\left(F_{15, R d}-F_{T 3_{1}}-F_{T 3_{2}}-F_{T 3_{3}}\right),\left(F_{25, R d}-F_{T 3_{2}}-F_{T 3_{3}}\right),\left(F_{35, R d}-F_{T 3_{3}}\right)\right]$ \\
\hline
\end{tabular}

Both figures represent the (Moment-Rotation) curve of the joint corresponding to each calculation. It is worth to mention that in order to reach a significant rotation of the joint, for both calculations an elastic- perfectly plastic behavior is adopted for all the components of the mechanical model. The algorithm is able to give the force at each bolt-row during the loading history. It can be easily observed that the equilibrium is always satisfied. These forces are highlighted at each point where the slop is changing.

For the first calculation (Fig. 21), it can observed that:

- At point "1" (Fig. 21) and at the point "A" (Fig.22), same distribution of forces is obtained. This step corresponds to the case where $T 3_{1}$ reaches its individual resistance. All other bolt-rows are still in elastic range.

- From point "2" (Fig. 21), the force at the Type T4 reaches its individual resistance (1011 $k N)$. Therefore, with respect to the equilibrium between tension and compression zones, the tension force is too low to activate a group effect.

- Point "3" (Fig. 21) corresponds to the maximum of the bending moment in the connection $\left(M_{j, \max }=567.5 k N . m\right)$. This obtained value is in accordance with the maximum value of the bending moment $\left(M_{j, \max }=567 \mathrm{kN} . \mathrm{m}\right)$ that obtained by Cerfontaine [13]. At this point an unloading of the force at $T 3_{4}$ to zero leads to a redistribution of this force to the upper bolt-rows which have not reaching their individual resistance yet $\left(T 3_{2}\right.$ and $\left.T 3_{3}\right)$. It appears that with this redistribution, $T 3_{2}$ reaches its individual resistance $(407 k N)$.

For the second calculation (Fig. 22), it can be observed that:

- At point $B$ (Fig. 22), the force at Type $T 4(1111,1 k N)$ is less than its resistance (1500 $k N)$. However, a group resistance is activated by $T 3_{2}$ and $T 3_{3}$. In accordance with Table 5 where $q=2$ and $\mathrm{s}=3$, it follows: 


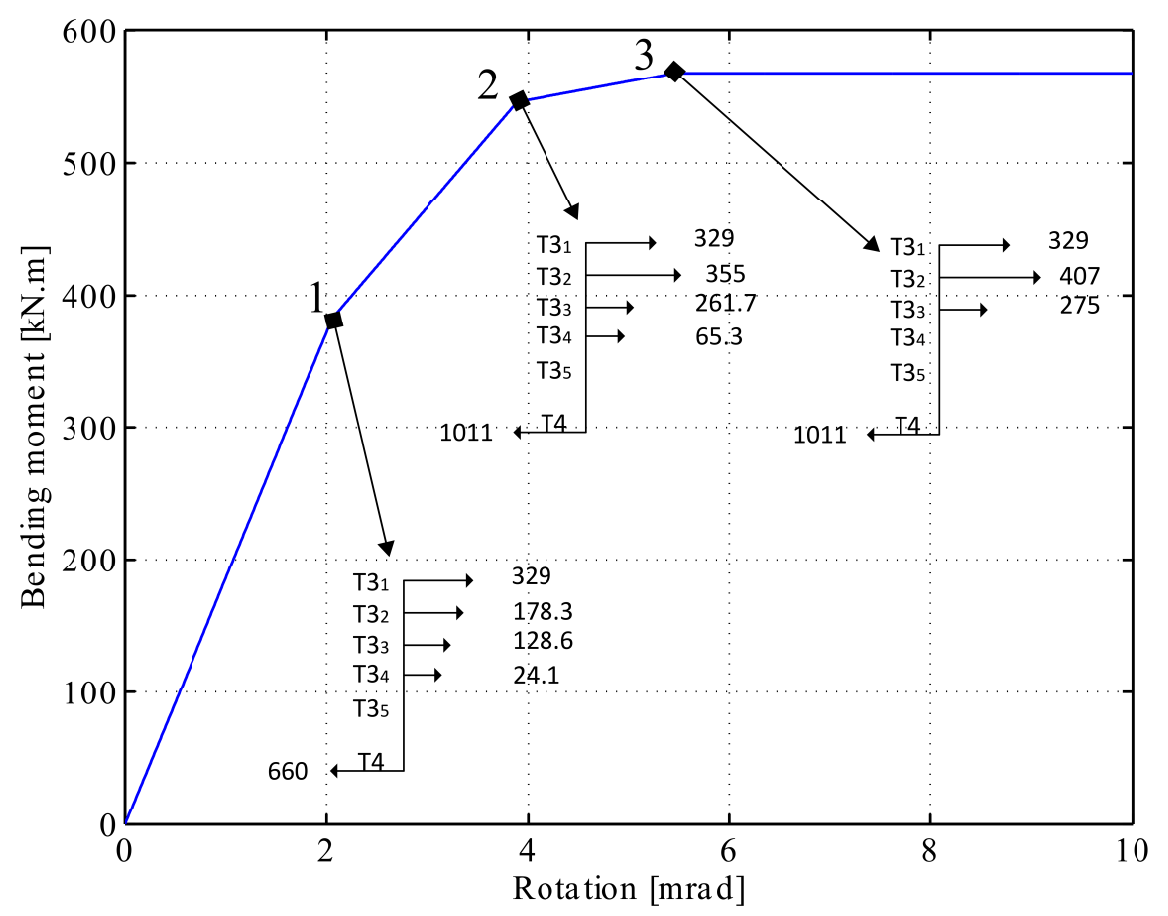

Figure 21: Moment vs. rotation curve

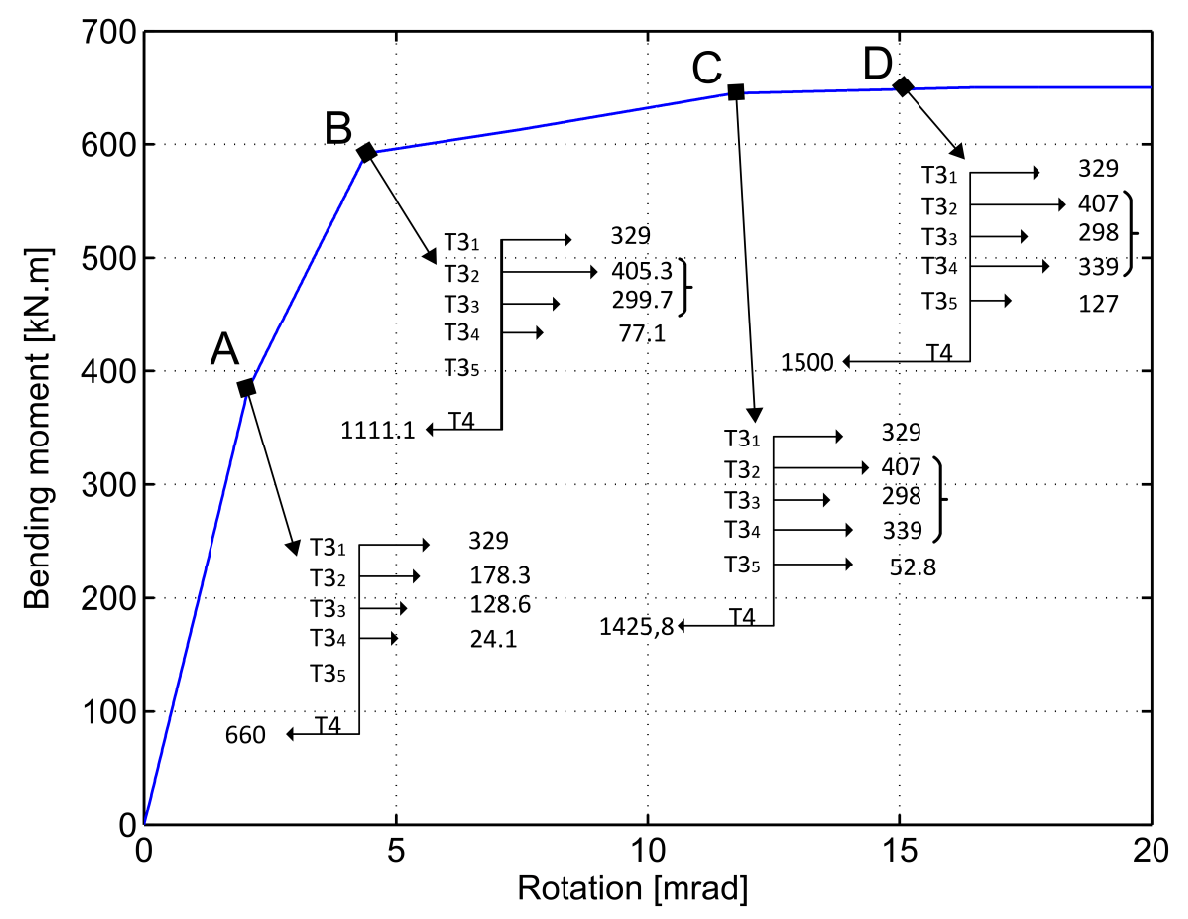

Figure 22: Moment vs. rotation curve 


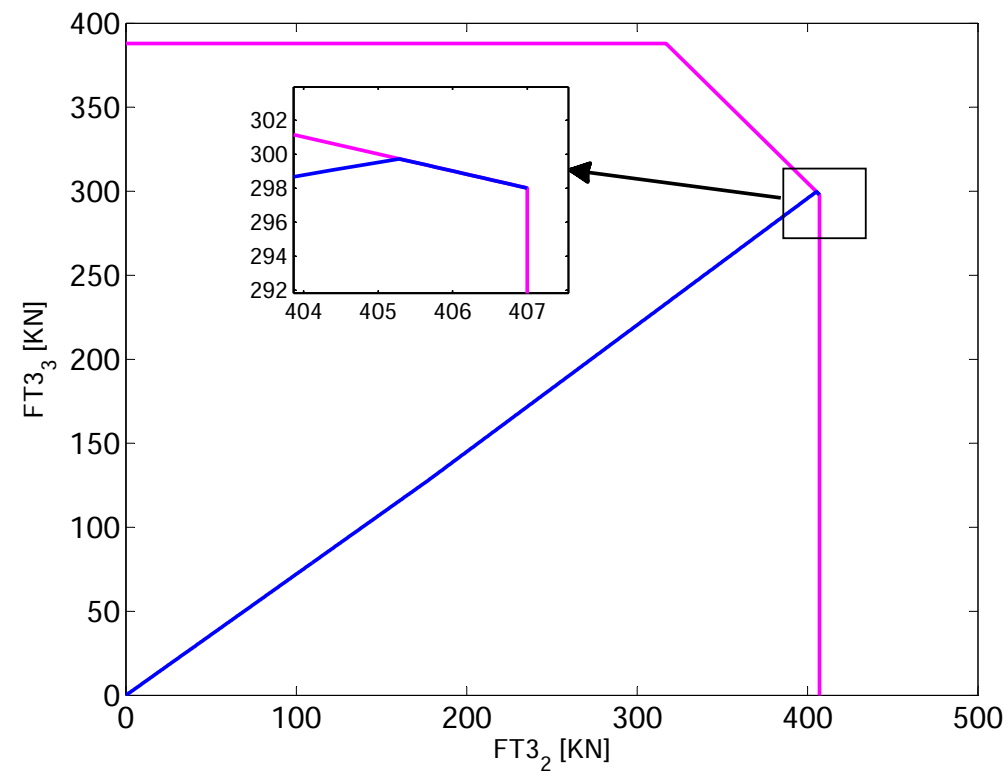

Figure 23: $\left(F_{T 3_{2}}-F_{T 3_{3}}\right)$ interaction diagram

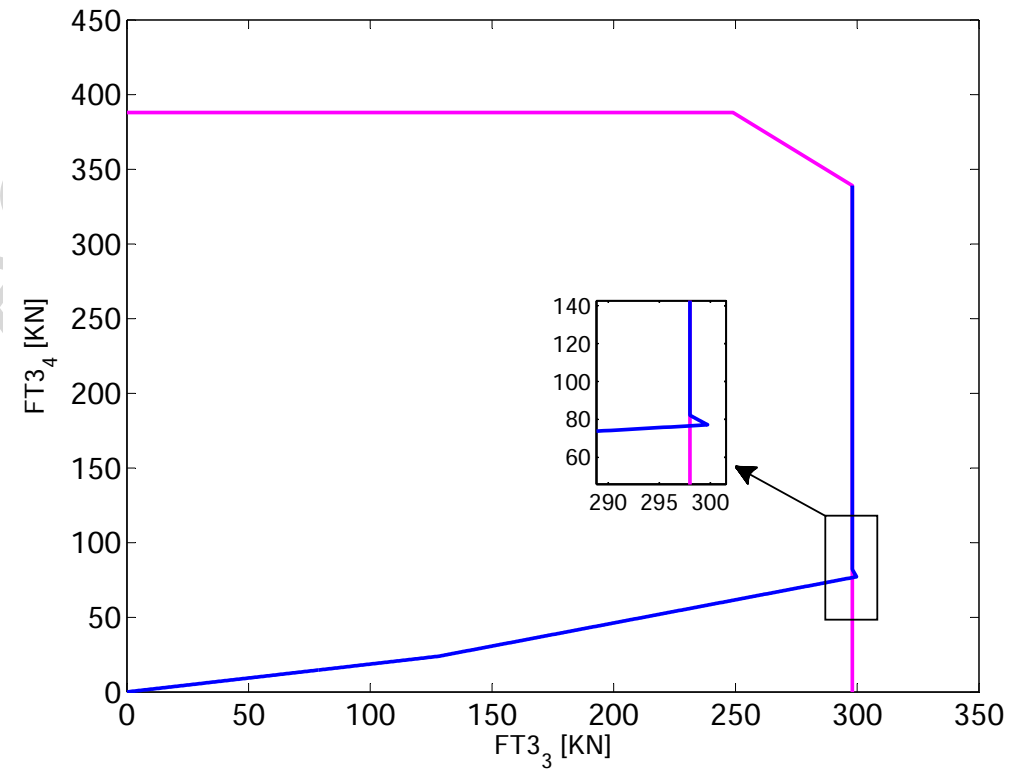

Figure 24: $\left(F_{T 3_{3}}-F_{T 3_{4}}\right)$ interaction diagram 
$405,3+299,7=705 k N=\operatorname{Min}[705,(1200-329=871 k N)]=705 k N$

- At point C (Fig. 22), the force at Type $T 4(1425,8 \mathrm{kN})$ is also less than its resistance $(1500 \mathrm{kN})$. On one hand, it can be observed that the activation of the previous group effect leads to a first influence on the redistribution force respecting the criterion of this group $(407+298=705 k N)$ (see Fig. 23 and Fig. 24). On the second hand, the group of 3 bolt-rows is activated by $T 3_{2}, T 3_{3}$ and $T 3_{4}$. In accordance with Table 5 where $q=3$ and $\mathrm{s}=4$, it follows:

$298+339=637 k N=\operatorname{Min}\left[\begin{array}{l}728,(1627-329-407=891 k N), \\ (1044-407=637 k N)\end{array}\right]=637 \mathrm{kN}$

It can be observed that the group of 3 bolt-rows is activated at this point.

- At point D (Fig. 22), the force at Type T4 reaches its resistance $(1500 k N)$. The bolt-rows from 1 to 4 are in plastic range (individual or group limit resistance). The force at the last bolt-row $T 3_{5}$ reaches the value $(127 \mathrm{kN})$ that insures the equilibrium between compression and tension zones. On one hand, it can be observed that the activation of the previous group effects leads to a first influence on the redistribution force respecting following criteria $(407+298=705 k N)$ and $(407+298+339=1044 k N)$. On the second hand, there is no other group effect activated. In accordance with Table 5 where $q=4$ and $\mathrm{s}=5$, it follows:

$$
339+127=466 k N<\operatorname{Min}\left[\begin{array}{l}
706,(1772-329-407-298=738 k N), \\
(1363-407-298=658 k N),(1046-298=748 k N
\end{array}\right]=658 k N
$$

\section{Conclusion}

The proposed beam-to-column joint model appears as an easy-to-compute tool. It is very useful in practice to be implemented in structural analysis code. It is based on the component-based analysis that is nowadays well-known by the designers of joints. It is worth to remind that its performance has been extended to solve the problem of the gap that could appear between the column flange and the end-plate during the cyclic loading. This problem has never been considered before, especially when it is included as a part of the plasticity algorithm.

In addition, the group effect of two bolt-rows has been detailed to show how to implement this effect into the plasticity algorithm. This model has been generalized to take into account the group effect including more than two bolt-rows.

Both phenomena have been developed for simple cases of joints in order to simplify the validation of the proposed model. Nevertheless, both improvements proposed to the component based-model remain available for any bolted end-plate connection configuration. 
i Concerning the gap effect, special care during computation is required for several tests that have to be computed for the gap to control the plasticity of each component within the joint. This care insures to approach the real behaviour of the joint including appropriate slipping to recover different gaps.

ii Concerning the solution proposed for the group effect, more the number of bolt-rows increases, more the number of criteria increases. The generalisation of the interaction formula has been easily verified for the case of a group of 3 bolt-rows and remains available for more.

\section{Acknowledgements}

The authors gratefully acknowledge the financial support provided by the European Commission (Research Fund for Coal and Steel) through the project ROBUST-IMPACT under grant agreement RFSR-CT-2012-00029.

\section{References}

[1] RICHARD, Ralph M., GILLETT, Paul E., KRIEGH, James D., et al. (1980). The analysis and design of single plate framing connections. Engineering Journal, 1980, vol. 17, no 2.

[2] Moncarz, P.D., Gerstle, K.H. (1981). Steel frames with non-linear connections. Journal of the Structural Division, ASCE, 107, $N^{\circ}$ ST8, Proc. paper 16440, 1427-1441.

[3] POGGI, C. et ZANDONINI, R. (1985) Behaviour and strength of steel frames with semi-rigid connections. In : Connection Flexibility and Steel Frames. ASCE, 1985. p. 57-76.

[4] Nethercot, D. (1989). Methods of prediction of joint behaviour: beam-to-column connections. Elsevier Applied Science, Structural Connections. Stability and Strength, 23-62.

[5] Patel, K. V., and Chen, W. F. (1985). Analysis of a fully bolted moment connection using NONSAP. Computers and structures, 1985, vol. 21, no 3, p. 505-511.

[6] Bursi, O. S., and Jaspart, J.P. (1997). Benchmarks for finite element modelling of bolted steel connections. Journal of Constructional Steel Research, 43(1), 17-42.

[7] Yang, J. G., Murray, T. M., and Plaut, R. H. (2000). Three-dimensional finite element analysis of double angle connections under tension and shear. Journal of Constructional Steel Research, 2000 , vol. 54 , no 2, p. 227-244.

[8] Maggi, Y.I., Goncalves, R.M. and Malite, M. (2002). Comparative analysis of bolted T-stub and corresponding extended endplate connections: a numerical approach European Conference on Steel Structure, Eurosteel 2002, Coimbra, 1199-1218.

[9] DÍAZ, Concepción, MARTÍ, Pascual, VICTORIA, Mariano, et al (2011). Review on the modelling of joint behaviour in steel frames. Journal of Constructional Steel Research, vol. 67, no 5, p. 741-758.

[10] YANG, Bo et TAN, Kang Hai. (2012). Component-based model of bolted-angle connections subjected to catenary action. In : Proc., 10th Int. Conf. on Advances in Steel Concrete Composite and Hybrid Structures.

[11] JASPART, J.P. (1996). Etude de la semi-rigidité des noeuds poutre-colonne et son influence sur la résistance et la stabilité des ossatures en acier (Doctoral dissertation). Université de liège, Belgique.

[12] JASPART, J.P., BRAHAM, M., et CERFONTAINE, F. (1999). Strength of joints subjected to combined action of bending moment and axial force. In : Proceedings of the Conference Eurosteel. 1999. p. 26-29.

[13] CERFONTAINE, F (2004). Étude de l'interaction entre moment de flexion et effort normal dans les assemblages boulonnés. Centre Technique Industriel de la Construction Métallique. 
[14] DEL SAVIO A.A., NETHERCOT D.A., VELLASCO P.C.G.S., S.A.L. ANDRADA, L.F. MARTHA et al. (2009). Generalised component-based model for beam-to-column connections including axial versus moment interaction. Journal of Constructional Steel Research, 2009, vol. 65, no 8, p. 1876-1895.

[15] BAYO, E., CABRERO, J. M., et GIL, B. (2006). An effective component-based method to model semirigid connections for the global analysis of steel and composite structures. Engineering Structures, vol. 28, no 1 , p. 97-108.

[16] LEMONIS, Minas E. et GANTES, Charis J. (2009). Mechanical modeling of the nonlinear response of beam-to-column joints. Journal of Constructional Steel Research, 65(4), 879-890.

[17] LIU, Chang, TAN, Kang Hai, et FUNG, Tat Ching. (2015). Component-based steel beam-column connections modelling for dynamic progressive collapse analysis. Journal of Constructional Steel Research, 107, 24-36.

[18] Mazzolani, F. M. (1988). Mathematical model for semi-rigid joints under cyclic loads. Connections in Steel Structurs: Behaviour, Strength and Design, Elsevier Applied Science Publishers, London, 112-120.

[19] Gang Shi, Yongjiu Shi, Yuanging Wang (2006). Behaviour of end-plate moment connections under earthquake loading. Engineering structures, 29(5), 703-716.

[20] YANG, Pu et EATHERTON, Matthew R. (2014). A phenomenological component-based model to simulate seismic behavior of bolted extended end-plate connections. Engineering Structures, 2014, vol. 75 , p. $11-26$.

[21] Da SILVA L.S., AHAHBAZIAN A., GENTILI F. and AUGUSTO H. (2016). Implementation of a component model for the cyclic behaviour of steel joints. Eighth International Workshop on Connections in Steel Structures, CONNECTIONS VIII, Boston, Massachusetts, USA

[22] DE LIMA, L. R. O., DA SILVA, L. Simoes, VELLASCO, PCG da S., et al. (2004). Experimental evaluation of extended endplate beam-to-column joints subjected to bending and axial force. Engineering Structures, 26(10), 1333-1347.

[23] Eurocode. 3 (2005). Design of steel structures, Part 1.8: Design of joints. Brussels: European Committee for Standardization.

[24] Krawinkler H. (1978). Shear design of steel frames joints AISC Engineering Journal, 15(3), 82-91.

[25] MARSDEN, SS Antman JE, WIGGINS, L. Sirovich S., GLASS, L., et al. (1993). Interdisciplinary Applied Mathematics Springer

[26] DA SILVA, L. Simoes, DE LIMA, L. R. O., , VELLASCO, PCG da S., et al. (2004). Behaviour of flush end-plate beam-to-column joints under bending and axial force. Steel and Composite Structures, Vol. 4, N0. $2,77-94$.

[27] BRODERICK, B. M. et THOMSON, A. W. (2002). The response of flush end-plate joints under earthquake loading. Journal of Constructional steel research, vol. 58, no 9, p. 1161-1175. 